\title{
Insight into ethylene interactions with molybdenum suboxide cluster anions from photoelectron spectra of chemifragments
}

Cite as: J. Chem. Phys. 148, 054308 (2018); https://doi.org/10.1063/1.5008264

Submitted: 04 October 2017 . Accepted: 22 January 2018. Published Online: 07 February 2018

Richard N. Schaugaard, Josey E. Topolski, Manisha Ray (D), Krishnan Raghavachari, and Caroline Chick Jarrold (i)

\section{ARTICLES YOU MAY BE INTERESTED IN}

Exotic electronic structures of $\mathrm{Sm}_{x} \mathrm{Ce}_{3-x} \mathrm{O}_{y}(x=0-3 ; y=2-4)$ clusters and the effect of high neutral density of low-lying states on photodetachment transition intensities

The Journal of Chemical Physics 149, 054305 (2018); https://doi.org/10.1063/1.5043490

Ce in the +4 oxidation state: Anion photoelectron spectroscopy and photodissociation of small $\mathrm{Ce}_{\mathrm{x}} \mathrm{O}_{\mathrm{y}} \mathrm{H}_{\mathrm{z}}{ }^{-}$molecules

The Journal of Chemical Physics 147, 104303 (2017); https://doi.org/10.1063/1.4996133

The electron shuffle: Cerium influences samarium $4 \mathrm{f}$ orbital occupancy in heteronuclear $\mathrm{Ce}-\mathrm{Sm}$ oxide clusters

The Journal of Chemical Physics 146, 194310 (2017); https://doi.org/10.1063/1.4983335

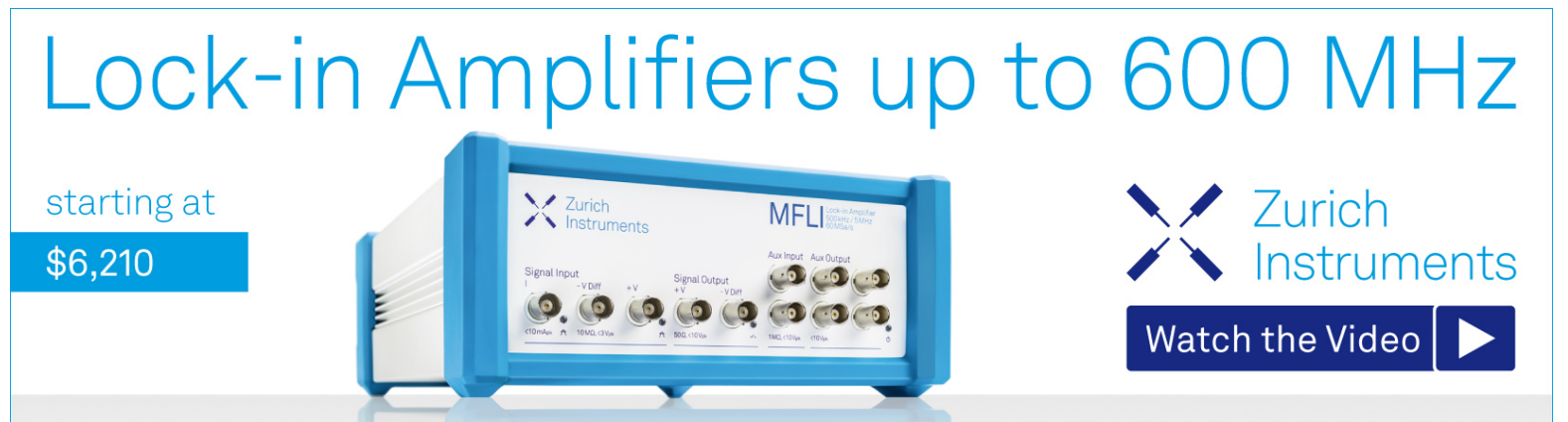




\title{
Insight into ethylene interactions with molybdenum suboxide cluster anions from photoelectron spectra of chemifragments
}

\author{
Richard N. Schaugaard, ${ }^{a}$ Josey E. Topolski, ${ }^{a}$ Manisha Ray, ${ }^{\text {b) }}$ Krishnan Raghavachari, \\ and Caroline Chick Jarrold ${ }^{\text {c) }}$ \\ Indiana University Department of Chemistry, 800 East Kirkwood Avenue, Bloomington, Indiana 47405, USA
}

(Received 4 October 2017; accepted 22 January 2018; published online 7 February 2018)

\begin{abstract}
Recent studies on reactions between $\mathrm{Mo}_{x} \mathrm{O}_{y}{ }^{-}$cluster anions and $\mathrm{H}_{2} \mathrm{O} / \mathrm{C}_{2} \mathrm{H}_{4}$ mixtures revealed a complex web of addition, hydrogen evolution, and chemifragmentation reactions, with chemifragments unambiguously connected to cluster reactions with $\mathrm{C}_{2} \mathrm{H}_{4}$. To gain insight into the molecularscale interactions along the chemifragmentation pathways, the anion photoelectron (PE) spectra of $\mathrm{MoC}_{2} \mathrm{H}_{2}{ }^{-}, \mathrm{MoC}_{4} \mathrm{H}_{4}^{-}, \mathrm{MoOC}_{2} \mathrm{H}_{2}^{-}$, and $\mathrm{MoO}_{2} \mathrm{C}_{2} \mathrm{H}_{2}{ }^{-}$formed directly in $\mathrm{Mo}_{x} \mathrm{O}_{y}{ }^{-}+\mathrm{C}_{2} \mathrm{H}_{4}(x>1$; $y \geq x$ ) reactions, along with supporting $\operatorname{CCSD}(\mathrm{T})$ and density functional theory calculations, are presented and analyzed. The complexes have spectra that are all consistent with $\eta^{2}$-acetylene complexes, though for all but $\mathrm{MoC}_{4} \mathrm{H}_{4}{ }^{-}$, the possibility that vinylidene complexes are also present cannot be definitively ruled out. Structures that are consistent with the PE spectrum of $\mathrm{MoC}_{2} \mathrm{H}_{2}{ }^{-}$differ from the lowest energy structure, suggesting that the fragment formation is under kinetic control. The $\mathrm{PE}$ spectrum of $\mathrm{MoO}_{2} \mathrm{C}_{2} \mathrm{H}_{2}{ }^{-}$additionally exhibits evidence that photodissociation to $\mathrm{MoO}_{2}{ }^{-}$ $+\mathrm{C}_{2} \mathrm{H}_{2}$ may be occurring. The results suggest that oxidative dehydrogenation of ethylene is initiated by Lewis acid/base interactions between the Mo centers in larger clusters and the $\pi$ orbitals in ethylene. Published by AIP Publishing. https://doi.org/10.1063/1.5008264
\end{abstract}

\section{INTRODUCTION}

Transition metal-organic frameworks, ${ }^{1}$ metal oxide and sulfide semiconductors, ${ }^{2-6}$ metal nanoparticles, ${ }^{7}$ and metalhydrogenase complexes ${ }^{8}$ have been explored as photocatalysts for $\mathrm{H}_{2}$ production from $\mathrm{H}_{2} \mathrm{O}$. Molybdenum oxides that are modestly substoichiometric, $\mathrm{MoO}_{3-x}(x<1)$ in particular, has shown potential as an electrocatalyst ${ }^{9}$ or photocatalyst ${ }^{10}$ for hydrogen evolution reactions (HERs). This material is appealing because it is low cost, stable, nontoxic, and environmentally benign. Characterizing the particular electronic and structural properties of oxygen vacancy defect sites that may enhance the catalytic activity ${ }^{11}$ of substoichiometric materials can be challenging in bulk or mesoporous materials because of the variety of vacancy sites and dilutions, beyond the continuously dynamic nature of metal oxide surfaces under catalytically active conditions. ${ }^{12}$

One approach to studying the local atomic-scale interactions that govern catalytic activation is the use of cluster models in both experimental and computational efforts. ${ }^{13-25}$ The mass specificity and computational tractability of cluster models can lend insights into the molecular scale interactions at defect sites that can complement surface models or more multivariate nano- and mesoscale materials studies.

We have reported a detailed picture of how water interacts with small Group 6 transition metal $(M=\mathrm{Mo}, \mathrm{W})$ suboxide cluster anions in ways that lead to $\mathrm{H}_{2}$ production ${ }^{26-29}$

\footnotetext{
a)R. N. Schaugaard and J. E. Topolski are co-first authors.

b)Current address: Sanford Burnham Prebys, 10901 North Torrey Pines Road, La Jolla, CA 92037, USA.

c)Author to whom correspondence should be addressed: cjarrold@indiana.edu
}

via

$$
M_{x} \mathrm{O}_{y}^{-}+\mathrm{H}_{2} \mathrm{O} \rightarrow M_{x} \mathrm{O}_{y+1}^{-}+\mathrm{H}_{2} .
$$

However, the production of trapped intermediates, $M_{x} \mathrm{O}_{y+1} \mathrm{H}_{2}{ }^{-}$, resulting from $\mathrm{H}_{2} \mathrm{O}$ addition to certain cluster anions in the oxidation pathway becomes more prevalent once the metal approaches its highest oxidation state, which is +6 . The reactivity data have also been interpreted computationally in terms of free energy reaction pathways, which point to the presence of high barriers to the $-\mathrm{H}$ and $-\mathrm{OH}$ rearrangement in the intermediate, preventing the thermodynamically favored $\mathrm{H}_{2}$ elimination from the intermediate. ${ }^{30-32}$

More recently, we completed a theoretical study on the feasibility of introducing a sacrificial reagent (SR) that could reduce the Mo-oxide cluster anions in particular, as they undergo oxidation by water, restoring the clusters to lower oxidation states necessary for $\mathrm{H}_{2}$ production. ${ }^{33}$ As a proof of principle, we considered the oxidation of $\mathrm{Mo}_{2} \mathrm{O}_{4}{ }^{-}$by water to form $\mathrm{Mo}_{2} \mathrm{O}_{5}{ }^{-}+\mathrm{H}_{2}$, with $\mathrm{Mo}_{2} \mathrm{O}_{5}{ }^{-}$being reduced by the SR. Acetylene, ethylene, propylene, and carbon monoxide served as SR models because they had favorable or near-thermoneutral reaction free energies with water:

$$
\mathrm{H}_{2} \mathrm{O}+\mathrm{SR} \stackrel{\mathrm{Mo}_{2} \mathrm{O}_{4}^{-}}{\longrightarrow} \mathrm{H}_{2}+S R O
$$

In the case of ethylene, the reaction is marginally endothermic by $2-3 \mathrm{kcal} / \mathrm{mol}$. However, the calculations suggested a potential pitfall in this approach; deeply bound complexes are formed between the clusters and the SR molecules. For example, in calculations on the $\mathrm{C}_{2} \mathrm{H}_{4}+\mathrm{H}_{2} \mathrm{O}+\mathrm{Mo}_{2} \mathrm{O}_{4}{ }^{-}$reaction, $\mathrm{Mo}_{2} \mathrm{O}_{5} \mathrm{C}_{2} \mathrm{H}_{4}{ }^{-}\left(+\mathrm{H}_{2}\right)$ emerged as a very stable complex that 
might interrupt the production of $\mathrm{C}_{2} \mathrm{H}_{4} \mathrm{O}$ necessary to achieve the full catalytic cycle.

From an experimental standpoint, the cluster anions gain considerable internal energy from new bond formation (in this case $\mathrm{Mo}-\mathrm{O}$ and $\mathrm{Mo}-\mathrm{C}$ bond formation) in the gas phase, which could result in complex fragmentation via the weakest bond. This effect was to some extent borne out in a follow-up experimental study ${ }^{34}$ on product distributions from $\mathrm{Mo}_{x} \mathrm{O}_{y}{ }^{-}$ clusters reacting individually with $\mathrm{C}_{2} \mathrm{H}_{4}$ and $\mathrm{H}_{2} \mathrm{O}$, and with those from reactions with a $\mathrm{C}_{2} \mathrm{H}_{4}+\mathrm{H}_{2} \mathrm{O}$ mixture. ${ }^{34}$ In addition to observing carbides $\left(-\mathrm{C}_{2}\right)$, acetylene $\left(-\mathrm{C}_{2} \mathrm{H}_{2}\right)$, and ethylidene $\left(-\mathrm{C}_{2} \mathrm{H}_{4}\right)$ metal oxo complexes, cluster anion complex fragmentation was also evident by the appearance of $\mathrm{MoO}_{y} \mathrm{C}_{2 n} \mathrm{H}_{2 n}{ }^{-}(y \leq 2, n=1,2)$ complexes that could not be accounted for by direct $\mathrm{C}_{2} \mathrm{H}_{4}$ addition reactions with $\mathrm{MoO}_{y}{ }^{-}$ $(y \leq 2)$ anions, which were either absent or in very low quantities in the initial cluster distribution. Indeed, the results of the experimental study underscored the need to reconsider the computational model of how the cluster anions interact with the ethylene molecules, including the expansion of potential side reactions that are possible along the multi-reactant free energy pathway. In this report, insight into how ethylene reacts with transition metal suboxide cluster anions is gained from the molecular and electronic structures of several prominent complexes evidently formed as chemifragments in reactions with larger clusters, $\mathrm{MoC}_{2} \mathrm{H}_{2}{ }^{-}, \mathrm{MoC}_{4} \mathrm{H}_{4}^{-}, \mathrm{MoOC}_{2} \mathrm{H}_{2}{ }^{-}$, and $\mathrm{MoO}_{2} \mathrm{C}_{2} \mathrm{H}_{2}^{-}$.

\section{METHODS}

\section{A. Experimental details}

$\mathrm{MoO}_{y} \mathrm{C}_{2 n} \mathrm{H}_{2 n}{ }^{-}(y \leq 2, n=1,2)$ and other complexes were generated, mass analyzed, and spectroscopically probed via anion photoelectron (PE) spectroscopy using a homebuilt experimental apparatus that has been described previously. ${ }^{35-37}$ Briefly, the $\mathrm{Mo}_{x} \mathrm{O}_{y}{ }^{-}$clusters are generated at a second harmonic output energy of $8 \mathrm{~mJ} /$ pulse of a Nd:YAG laser $(532 \mathrm{~nm}, 2.33 \mathrm{eV})$ operated at a $30 \mathrm{~Hz}$ repetition rate ablated on a pressed rotating ${ }^{98}$ Mo metal target (Trace Sciences). The resulting plasma was then entrained in a pulse of ultrahigh purity (UHP) helium carrier gas [30 psi (gauge) stagnation pressure] issued from a pulsed molecular beam valve operated at a $30 \mathrm{~Hz}$ repetition rate and swept into a 25-mm long, 3-mm diameter reaction channel. A second molecular beam valve operated at the same repetition rate $(30 \mathrm{~Hz})$ was used to introduce $\mathrm{C}_{2} \mathrm{H}_{4}$ into the reaction channel.

The resulting gas mixture expanded into a vacuum chamber and was collimated by using a 3-mm diameter skimmer. The anions were accelerated on the molecular beam axis into a $1.2-\mathrm{m}$ TOF mass spectrometer, passed through a $3-\mathrm{mm}$ mass defining slit in a detection region, and collided with a 25-mm microchannel plate (MCP) detector assembly. The resulting signal from the detector is then recorded with a digitizing oscilloscope. The mass resolution, $\left(\frac{m}{\Delta m}\right)$, in the range of ion masses for this study is 300 . Mass distributions were recorded before, during, and after the introduction of $\mathrm{C}_{2} \mathrm{H}_{4}$ to ensure that complexes were not formed from deposits on the target resulting from the back-streaming of $\mathrm{C}_{2} \mathrm{H}_{4}$ in the target region.

Prior to colliding with the ion detector, ions were selectively photodetached using one of the harmonic outputs of a second Nd:YAG laser timed to intersect a specific ion packet. A small fraction of the photoelectrons traveled the length of a 1-m long field-free drift tube and were detected with a second MCP detector. The drift times were recorded with a digitizing oscilloscope and converted to electron kinetic energy, $e^{-} K E$, calibrated with the well-known PE spectrum of $\mathrm{Mo}^{-} .^{38}$ The $e^{-} K E$ values are related to the relative energies of the neutral states relative to the initial anion state via

$$
e^{-} \boldsymbol{K E}=\boldsymbol{h} v-E A-E_{\text {internal }}^{\text {neutral }}+E_{\text {internal }}^{\text {anion }},
$$

where $E A$ is the neutral electron affinity. The PE spectra are shown as electron counts versus electron binding energy $\left(e^{-} B E\right)$ values, with the relationship:

$$
e^{-} B E=h v-e^{-} K E .
$$

Spectra were collected with the detachment laser polarization parallel to $\left(\theta=0^{\circ}\right)$ and perpendicular to $\left(\theta=90^{\circ}\right)$ the electron drift path to approximate the asymmetry parameter, $\beta(E)$ :

$$
\boldsymbol{\beta}=\frac{\left(\boldsymbol{I}_{0}-\boldsymbol{I}_{90}\right)}{\left(\frac{1}{2} \boldsymbol{I}_{0}+\boldsymbol{I}_{90}\right)},
$$

which gives some insight into the nature of the molecular orbital associated with the various electronic transitions observed in the PE spectra. For example, detachment transitions associated with Mo-local $5 s$-like molecular orbitals would be expected to have parallel photoelectron angular distributions $(\beta=2)$, while detachment transitions from $\pi$-like orbitals might have more isotropic $(\beta=0)$ or perpendicular $(\beta=-1)$ photoelectron angular distributions.

The PE spectra presented below were accumulated over $1.8 \times 10^{6}$ laser shots for $\mathrm{MoC}_{2} \mathrm{H}_{2}{ }^{-}$using $3.49 \mathrm{eV}$ photon energy and $2.9 \times 10^{6}$ laser shots using $2.33 \mathrm{eV}$ photon energy, $0.9 \times 10^{6}$ laser shots for $\mathrm{MoC}_{4} \mathrm{H}_{4}{ }^{-}(3.49 \mathrm{eV}$ photon energy, only), $0.65 \times 10^{6}$ laser shots for $\mathrm{MoOC}_{2} \mathrm{H}_{2}{ }^{-}(3.49 \mathrm{eV}$ photon energy, only), and $2.5 \times 10^{6}$ laser shots for $\mathrm{MoO}_{2} \mathrm{C}_{2} \mathrm{H}_{2}{ }^{-}$ ( $3.49 \mathrm{eV}$ photon energy, only). The resolution is approximately $6 \mathrm{meV}$ at $e^{-} K E=0.5 \mathrm{eV}$ and deteriorates with $e^{-} K E^{3 / 2}$.

\section{B. Computational details}

Calculations were performed with the quantum chemical program package Gaussian $09^{39}$ using the hybrid exchangecorrelation functional B3LYP for structural optimization, followed by single point B3LYP and CCDS(T) calculations. ${ }^{40-42}$ Geometry optimizations of the various chemical species, vibrational mode calculations, based on the unrestricted KohnSham density functional theory (UKSDFT) and energies were done with the def2-SVPP basis set. ${ }^{43,44}$ As demonstrated to be effective previously ${ }^{45}$ the 28 core electrons of Mo were modeled using the Stuttgart/Dresden effective core potential. ${ }^{45,46}$ Accurate electronic energies were obtained with a basis set consisting of the def2-TZVPP basis functions supplemented by the addition of diffuse functions from the aug-cc-PVTZ basis set $^{47}$ for the main group elements and $\mathrm{S}, \mathrm{P}$, and $\mathrm{D}$ diffuse functions with exponents $0.0045,0.0070821$, and 
0.0129 respectively for Mo. Only local minimum energy structures (no imaginary frequencies) are reported except for one single point calculation performed on a triplet state of $\mathrm{MoC}_{4} \mathrm{H}_{4}$ confined to the $\mathrm{D}_{2 \mathrm{~d}}$ symmetry. Zero point energy (ZPE) corrections were obtained for polyatomic species from vibrational frequency calculations performed analytically. Time-dependent density-functional theory (TD-DFT) calculations using the B3LYP and the Def2-TZVPP basis set were performed to determine the lowest 12 excited states of the most stable neutral structures. We also performed calculations using the M06 functional (structures and relative energies are included in the supplementary material). The inclusion of the Hartree-Fock (HF) exchange in both functionals systematically overstabilizes high spin states relative to low spin states. ${ }^{48}$ We found in this study that the larger contribution of the HF exchange in M06 compared to that of B3LYP (27\% versus 20\%) resulted in poorer agreement between experimental transition energies and those calculated using the M06 functional compared with the B3LYP results. For most of the systems described below, the relative energies calculated at the $\operatorname{CCSD}(\mathrm{T})$ and B3LYP levels of theory were in good agreement. Only the $\operatorname{CCSD}(\mathrm{T})$ values are reported below; a side-by-side comparison of the B3LYP and $\operatorname{CCSD}(\mathrm{T})$ relative energies is included in the supplementary material.

All CCSD $(T)$ calculations were unrestricted and were performed starting with the unrestricted Hartree-Fock orbitals. The spin contamination in the resulting wavefunctions was monitored carefully. Since CCSD is known to effectively correct for the first spin contaminant, the starting Hartree-Fock $\left\langle\mathrm{S}^{2}\right\rangle$ values after removing the first contaminant are reported in Tables II-V In a few cases, Brueckner orbital studies were carried out to check for the nature of the wavefunctions after orbital rotations, and the $\left\langle\mathrm{S}^{2}\right\rangle$ values are reported from the Brueckner orbitals when available. In most cases, the tabulated $\left\langle S^{2}\right\rangle$ values are quite close to the ideal $\left\langle S^{2}\right\rangle$ values. We expect that the energy contributions from the residual spin contamination effects are small.

TDDFT calculations were also performed to assess the possibility of one-electron allowed excited state transitions. The states that were determined to be one-electron accessible from the various anion states were also optimized.

For more quantitative comparison between the calculated structures and the experimental spectra, the simulated spectra were generated with the following parameters taken into consideration. Adiabatic detachment energies (ADEs) are computed from the difference between the zero-point corrected total energies of the anion and one-electron accessible (and Franck-Condon rational) neutral states. ADEs correspond to the origins of anions to neutral detachment transitions. A vibrational structure within an electronic transition was simulated using home-written Labview codes that calculate the normal coordinate displacements of the anion structure along the neutral normal coordinates from input anions and neutral atomic Cartesian coordinates and the neutral normal coordinates from the Gaussian output files. The code automatically sets the molecular structures at the same center of mass. The "Solve Complex Linear Equations" subVI in the Labview Advanced Math Package, $\mathrm{AX}=\mathrm{Y}$ solves for $\mathrm{X}$, where $\mathrm{X}$ is the $3 \mathrm{~N}-6$ normal coordinate displacement vector, $\mathrm{Y}$ is the $3 \mathrm{~N}$ Cartesian displacement vector computed from the input atomic Cartesian coordinates for the anion and neutral, and $\mathrm{A}$ is the $3 \mathrm{~N} \times 3 \mathrm{~N}$ -6 normal coordinate matrix from the neutral Gaussian output file. The normal coordinate displacements, anion and neutral vibrational frequencies, ADE values, and photon energy (for $e^{-} K E$ calculation) are then input into a second code that generates harmonic oscillator wavefunctions, numerically calculates the Franck-Condon factors, and generates a simulation with vibronic line positions and $e^{-} K E$-dependent linewidths. Vibrational temperatures can be adjusted independently for each mode activated.

Transitions with significant structural differences that would result in the activation of multiple low-frequency modes are not treated appropriately using the harmonic oscillator, a parallel mode approach used in this set of simulation codes described above. Since this type of transition would yield broad bands with an unresolved vibrational structure, we simply generated a broad band originating at the computed ADE with maximum intensity coinciding with the computed vertical detachment energy, VDE. VDEs are computed by taking the difference between the total electronic energy of a one-electron accessible neutral confined to the structure of the anionic precursor and the total electronic energy of the optimized anion.

\section{RESULTS AND ANALYSIS}

Figure 1 shows characteristic mass spectra recorded in the 100 to $200 \mathrm{~m} / \mathrm{z}$ range for the ions generated from ablation of the ${ }^{98}$ Mo target with He carrier gas (dotted trace) along with the mass distribution of ions generated in reactions with $\mathrm{C}_{2} \mathrm{H}_{4}$ in the fast flow reaction channel (solid trace). Note that $\mathrm{MoO}_{y} \mathrm{C}_{m} \mathrm{H}_{n}{ }^{-}$products with $y \leq 2$ are significantly more abundant than the initial $\mathrm{MoO}_{2}{ }^{-}$ion intensity, and $\mathrm{MoO}^{-}$(and $\mathrm{Mo}^{-}$, at $98 \mathrm{amu}$, not shown in Fig. 1) ions are not present in the initial mass spectrum. Based on previous studies, $\mathrm{MoO}_{y} \mathrm{C}_{m} \mathrm{H}_{n}{ }^{-}$ products $(y<3)$ are formed via chemifragmentation of larger

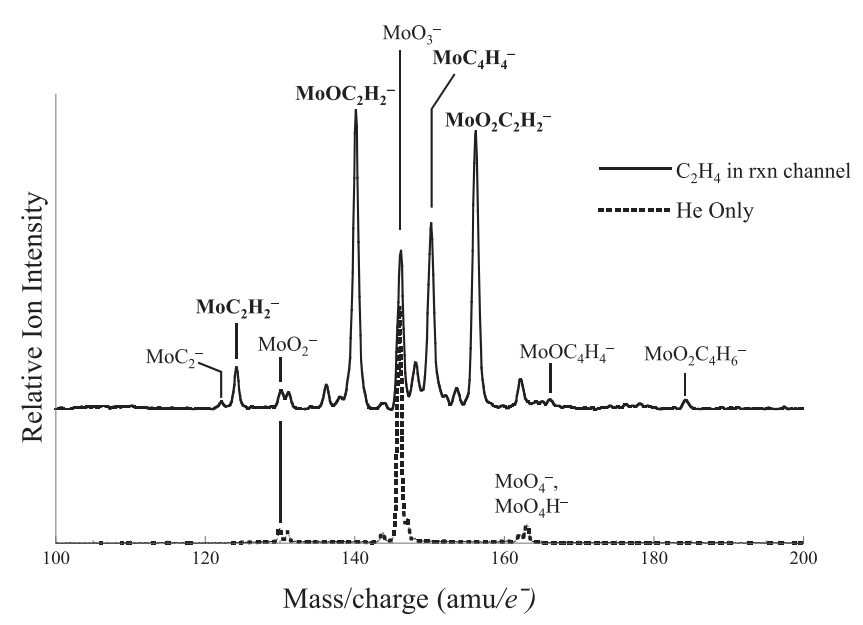

FIG. 1. Mass spectra in the mono- ${ }^{98}$ Mo complex mass range. The dotted trace shows the initial mass distribution, with the solid trace showing the distribution following cluster reactions with $\mathrm{C}_{2} \mathrm{H}_{4}$. The PE spectra of the species labeled in bold face are shown in Fig. 2. 
$\mathrm{Mo}_{x} \mathrm{O}_{y}{ }^{-}$at the lower end of the distribution of oxidation states (e.g., $\mathrm{Mo}_{2} \mathrm{O}_{2,3}{ }^{-}$and $\mathrm{Mo}_{3} \mathrm{O}_{3,4}{ }^{-}$) upon reaction with $\mathrm{C}_{2} \mathrm{H}_{4}$.

Figure 2 shows the anion $\mathrm{PE}$ spectra of $\mathrm{Mo}^{-}, \mathrm{MoC}_{2} \mathrm{H}_{2}{ }^{-}$, $\mathrm{MoC}_{4} \mathrm{H}_{4}{ }^{-}, \mathrm{MoOC}_{2} \mathrm{H}_{2}{ }^{-}$, and $\mathrm{MoO}_{2} \mathrm{C}_{2} \mathrm{H}_{2}{ }^{-}$. The PE spectrum of $\mathrm{Mo}^{-}$, previously reported by Lineberger and co-workers, ${ }^{38}$
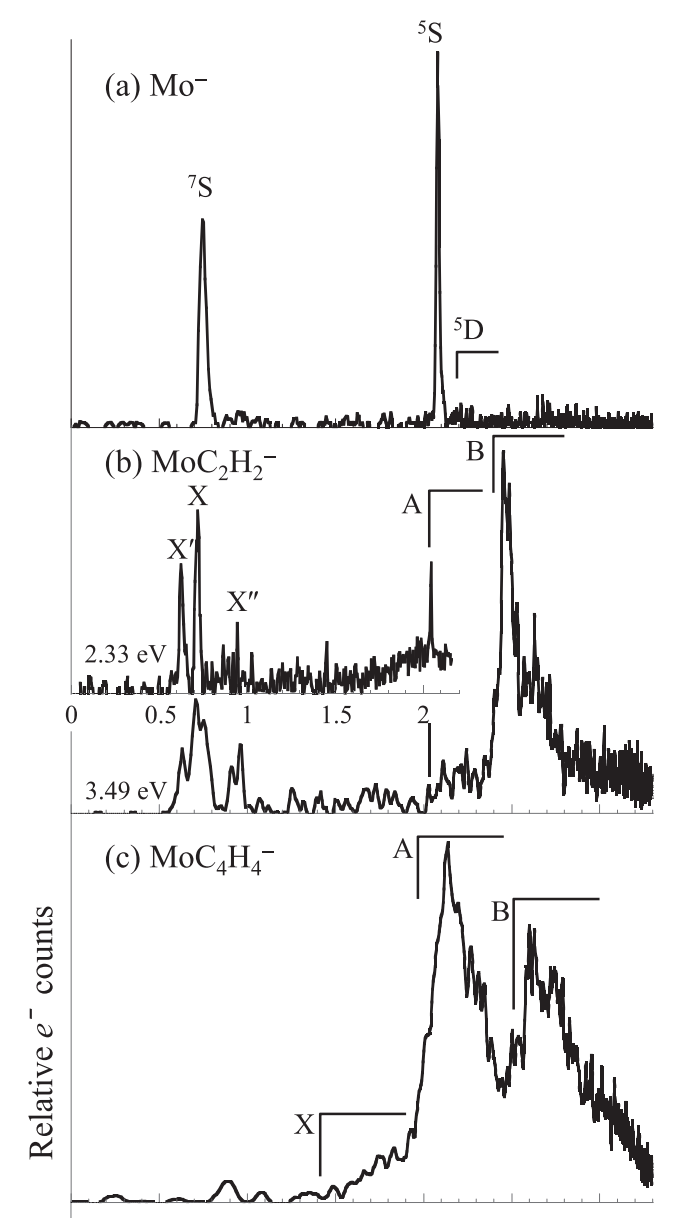

(d) $\mathrm{MoOC}_{2} \mathrm{H}_{2}^{-}$
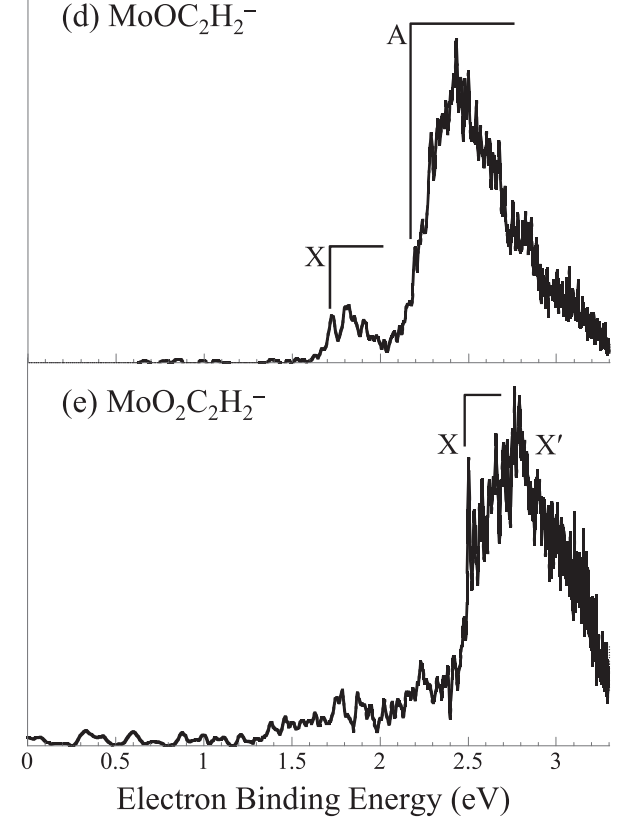

FIG. 2. PE spectra obtained using $3.49 \mathrm{eV}$ photon energy: (a) ${ }^{98} \mathrm{Mo}^{-}$, (b) ${ }^{98} \mathrm{MoC}_{2} \mathrm{H}_{2}{ }^{-}$(the inset shows the PE spectrum obtained using $2.33 \mathrm{eV}$ photon energy), (c) ${ }^{98} \mathrm{MoC}_{4} \mathrm{H}_{4}^{-}$, (d) ${ }^{98} \mathrm{MoOC}_{2} \mathrm{H}_{2}{ }^{-}$, and (e) ${ }^{98} \mathrm{MoO}_{2} \mathrm{C}_{2} \mathrm{H}_{2}{ }^{-}$. was included to directly illustrate the comparability of the transition energies between the atomic anion and the complex anions. All spectra of the complexes exhibit at least two electronic transitions, many of which feature broad, vibrationally congested profiles. Transition energies and asymmetry parameters for these bands are summarized in Table I. Computational results are summarized pictorially in Figs. 3-6 and Tables II-V. TDDFT excited state energies are included in the supplementary material. A general computational result is that high spin states are favored for all complex anions and neutrals except $\mathrm{MoO}_{2} \mathrm{C}_{2} \mathrm{H}_{2}\left({ }^{2} \mathrm{~A}_{1}\right.$ anion ground state; ${ }^{1} \mathrm{~A}_{1}$ neutral ground state), in which the metal is mostly coordinated. The remaining complexes are therefore expected to have numerous close-lying states with a common spin associated with the close-lying Mo-local $4 d$ orbitals. Spin contamination effects are present in several states, as reflected in the $\left\langle S^{2}\right\rangle>S(S+1)$ values included in Tables II-V.

\section{A. $\mathrm{MoC}_{2} \mathrm{H}_{2}-/ \mathrm{MoC}_{2} \mathrm{H}_{2}$}

The PE spectrum of $\mathrm{MoC}_{2} \mathrm{H}_{2}{ }^{-}$shown in Fig. 2(b) obtained using $3.49 \mathrm{eV}$ photon energy exhibits low-intensity bands in the range of $0.6-0.9 \mathrm{eV}$ that lack regular vibrational spacings. A broad band labeled A rises from the baseline at 2.03 $\pm 0.05 \mathrm{eV}$, with a much more intense band $\mathrm{B}$ originating at $2.41 \pm 0.05 \mathrm{eV}$. The inset of Fig. 2(b) shows the PE spectrum obtained using $2.33 \mathrm{eV}$ photon energy. This spectrum clearly resolves two close-lying transitions, $\mathrm{X}$ and $\mathrm{X}^{\prime}$, at 0.718 $\pm 0.010 \mathrm{eV}$ and $0.626 \pm 0.010 \mathrm{eV}$, respectively, while the feature at $0.92 \pm 0.04 \mathrm{eV}$, labeled $\mathrm{X}^{\prime \prime}$, appears less distinct in the $2.33 \mathrm{eV}$ spectrum than that in the $3.49 \mathrm{eV}$ spectrum. Bands $X, X^{\prime}$, and $X^{\prime \prime}$ are parallel $(\beta=2)$, while the remaining transitions are nearly isotropic $(\beta=0)$ with respect to laser polarization.

Figure 3 and Table II summarize the computational results for the $\mathrm{MoC}_{2} \mathrm{H}_{2}$ anion and neutral. The lowest energy structure of the anion found computationally is a linear structure in which the Mo inserts into a $\mathrm{C}-\mathrm{H}$ bond in acetylene, in a ${ }^{6} \Sigma$ state, labeled $\mathbf{I}$ in Fig. 3(a) and Table II. A $\mathrm{C}_{2 \mathrm{v}}$ molybdenumvinylidene structure in ${ }^{4} \mathrm{~B}_{2}$ state, $\mathbf{I I}$, is calculated to be $0.64 \mathrm{eV}$ higher in energy, and a triangle-shaped $\mathrm{C}_{2 \mathrm{v}} \operatorname{Mo}\left(\eta^{2}-\right.$ acetylene) complex, III, is calculated to have close-lying ${ }^{6} \mathrm{~B}_{2}$ and ${ }^{4} \mathrm{~B}_{2}$ states, lying $0.55 \mathrm{eV}$ and $0.63 \mathrm{eV}$ higher in energy than the linear structure. The two spin states of the anion of structure III represent the only disparity between the $\operatorname{CCSD}(\mathrm{T})$ and B3LYP calculations; the ${ }^{4} \mathrm{~B}_{2}$ state was predicted to be $0.06 \mathrm{eV}$ lower in energy than the ${ }^{6} \mathrm{~B}_{2}$ state with B3LYP. The calculations do, however, agree that these states are competitive, and approximately $0.5 \mathrm{eV}$ higher in energy than the linear structure I (see the supplementary material).

The energetic ordering of the neutral structures is different from the anions, with the $\operatorname{Mo}\left(\eta^{2}\right.$-acetylene) complex ${ }^{5} B_{2}$ state being the lowest energy. The calculated ADE value of structure I (Table II), $1.45 \mathrm{eV}$, is in poor agreement with the low binding energy of bands $\mathrm{X}, \mathrm{X}^{\prime}$ and $\mathrm{X}^{\prime \prime}$ in the experimental spectrum, while the ADEs calculated for structures II and III, which lie between 0.5 and $0.9 \mathrm{eV}$, are both in reasonable agreement. The frontier orbitals associated with the detachment transitions are included in the supplementary material. 
TABLE I. Transition energies in the PE spectra of $\mathrm{MoC}_{2} \mathrm{H}_{2}{ }^{-}, \mathrm{MoC}_{4} \mathrm{H}_{4}^{-}, \mathrm{MoOC}_{2} \mathrm{H}_{2}{ }^{-}$, and $\mathrm{MoO}_{2} \mathrm{C}_{2} \mathrm{H}_{2}{ }^{-}$shown in Fig. 2. The values in parentheses reflect the uncertainty in the last digit or digits.

\begin{tabular}{|c|c|c|c|c|}
\hline & Band & ADE/VDE (eV) & $\beta$ & Tentative assignment \\
\hline \multirow{5}{*}{$\mathrm{MoC}_{2} \mathrm{H}_{2}^{-}$} & $\mathrm{B}$ & $2.41(5) / 2.45(5)$ & 0 & \multirow{3}{*}{$\begin{array}{l}\text { Transitions to excited quintet and/or } \\
\text { triplet neutral states (see text) }\end{array}$} \\
\hline & A & $2.03(5) / 2.2(1)$ & 0 & \\
\hline & $X^{\prime \prime}$ & $0.92(4)$ & 2 & \\
\hline & $\mathrm{X}$ & $0.718(10)$ & 2 & \multirow{2}{*}{$\begin{array}{l}\text { Structure II }{ }^{5} \mathrm{~B}_{2}-{ }^{4} \mathrm{~B}_{2} \\
\text { Structure III I }{ }^{5} \mathrm{~B}_{2}-{ }^{6} \mathrm{~B}_{2}\end{array}$} \\
\hline & $\mathrm{X}^{\prime}$ & $0.626(10)$ & 2 & \\
\hline \multirow{3}{*}{$\mathrm{MoC}_{4} \mathrm{H}_{4}^{-}$} & B & $2.5(2) / 2.6(1)$ & 0 & \multirow{3}{*}{$\begin{array}{l}\text { Structure } \mathbf{I}^{5} \mathrm{~A}^{\prime}-{ }^{4} \mathrm{~A}_{2} \\
\quad(\text { See text }) \\
\text { Structure } \mathbf{I}^{3} \mathrm{~A}^{\prime}-{ }^{4} \mathrm{~A}_{2}\end{array}$} \\
\hline & A & $2.0(1) / 2.14(5)$ & 0 & \\
\hline & $\mathrm{X}$ & $1.5(1) / 1.75(10)$ & 0 & \\
\hline \multirow{3}{*}{$\mathrm{MoOC}_{2} \mathrm{H}_{2}^{-}$} & A & $2.1(1) / 2.45(3)$ & $0.5(1)$ & \multirow{3}{*}{$\begin{array}{c}\text { Transition to excited triplet } \\
\text { neutral state (see text) } \\
\text { Structure } \mathrm{I}^{3} \mathrm{~A}-{ }^{4} \mathrm{~A}^{\prime \prime}\end{array}$} \\
\hline & & & & \\
\hline & $\mathrm{X}$ & $1.68(7) / 1.80(5)$ & $0.4(1)$ & \\
\hline \multirow{3}{*}{$\mathrm{MoO}_{2} \mathrm{C}_{2} \mathrm{H}_{2}^{-}$} & $\mathrm{X}$ & $2.51(7) / 2.6(1)$ & $0.3(1)$ & \multirow[t]{2}{*}{ Structure $\mathbf{I}{ }^{1} \mathrm{~A}_{1}-{ }^{2} \mathrm{~A}_{1}$} \\
\hline & $\mathrm{X}^{\prime}$ & $2.4(2) / 2.8(2)$ & 0 & \\
\hline & \multicolumn{4}{|c|}{$\begin{array}{l}\text { (Additional continuum signal at } e^{-} B E>1.3 \mathrm{eV} \text { with local maxima ca. } 1.75 \mathrm{eV} \\
\text { and } 2.25 \mathrm{eV} \text { ) }\end{array}$} \\
\hline
\end{tabular}

Simulations based on the zero-point corrected ADE values, the calculated normal coordinate displacements, and the anion and neutral vibrational frequencies for the lowest energy transitions for each structure are shown as blue traces in Figs. 3(b)-3(d). In the case of the vinylidene (II) and $\eta^{2}-$ acetylene structures (III), the nearly isoenergetic quartet anion states can access both the lowest energy quintet and various excited triplet neutral states, though in the case of structure II, the lowest lying triplet state is not one-electron allowed. The sextet state of the $\eta^{2}$-acetylene structure (III) can access multiple low-lying excited quintet states. The maximum intensities of all bands were set equal to each other, except in panel 3(e), in which the simulations are scaled to hypothetically match the spectrum. All simulation parameters are included in the supplementary material. We note here that not all transitions are anticipated to have the same cross section. To underscore this point, the PE spectrum of $\mathrm{Mo}^{-}$shown in Fig. 2(a) exhibits two intense transitions associated with the photodetachment of an electron from the $5 s$ orbital of $\mathrm{Mo}^{-}$, while the transitions to the spin-orbit components of the ${ }^{5} \mathrm{D}$ state, which involves detachment of an electron from a $4 d$ orbital, are barely discernable from the baseline.

The simulated ${ }^{5} \mathrm{~A}^{\prime}-{ }^{6} \Sigma$ transition of structure $\mathbf{I}$, shown in Fig. 3(b), further reinforces the disagreement between the observed spectrum and the spectrum predicted for the lowest energy anion found computationally. The simulation of the lowest energy ${ }^{5} \mathrm{~B}_{2}-{ }^{4} \mathrm{~B}_{2}$ transition of structure II [blue trace, Fig. 3(c)] is nearly vertical, as is the ${ }^{5} B_{2}-{ }^{4} B_{2}$ electronic hot band transition of structure III [blue dashed trace, Fig. 3(d)], while the structure III ground ${ }^{5} \mathrm{~B}_{2}-{ }^{6} \mathrm{~B}_{2}$ transition [blue solid trace, Fig. 3(d)] shows a modest vibrational progression in the $553 \mathrm{~cm}^{-1}$ Mo- $\left(\eta^{2}\right.$-acetylene $)$ stretch. The orbitals associated with the ${ }^{5} \mathrm{~B}_{2}-{ }^{4} \mathrm{~B}_{2}$ transitions of structure $\mathbf{I I}$ and both the ${ }^{5} \mathrm{~B}_{2}-$ ${ }^{6} \mathrm{~B}_{2}$ and ${ }^{5} \mathrm{~B}_{2}-{ }^{4} \mathrm{~B}_{2}$ transitions of structure III can be described as predominantly Mo $5 s$-like molecular orbitals (see the supplementary material), which is consistent with the parallel photoelectron angular distributions $(\beta=2)$. Both structures II and III are predicted to exhibit multiple close-lying transitions in the region of band B in the experimental spectrum. Simulations based on the optimized one-electron accessible excited state structures are shown for the anion ground states of structures II and III in Figs. 3(c) and 3(d), respectively, while the positions of the transitions predicted for the close-lying ${ }^{4} \mathrm{~B}_{2}$ excited anion state of structure III are indicated with dashed lines in Fig. 3(d).

In sum, the simulations do not unambiguously support either the vinylidene (II) or the $\eta^{2}$-acetylene (III) structures. The presence of three features that are consistent with energy, profile, and photoelectron angular distribution could suggest that both species are present, and both close-lying spin states of structure III contribute to the spectrum. From an electronic structure standpoint, the two species are similar. Multiple excited state transitions are predicted for both species to lie in the energy window between bands A and B. However, the calculations, in comparison with the experimental spectrum, unambiguously eliminate the lowest energy isomer of the anion identified computationally.

\section{B. $\mathrm{MoC}_{4} \mathrm{H}_{4}-/ \mathrm{MoC}_{4} \mathrm{H}_{4}$}

The PE spectrum of $\mathrm{MoC}_{4} \mathrm{H}_{4}{ }^{-}$shown in Fig. 2(c) shows three broad, overlapping transitions, labeled $\mathrm{X}, \mathrm{A}$, and $\mathrm{B}$. Because of the spectral congestion, the origins of these transitions are difficult to identify, but are at $e^{-} B E$ values of approximately $1.5 \mathrm{eV}, 2.0 \mathrm{eV}$, and $2.5 \mathrm{eV}$, as summarized in Table I. Band A, the most intense and narrow of the overlapping bands, exhibits a shoulder to higher $e^{-} B E$ at approximately 1300 $\pm 100 \mathrm{~cm}^{-1}$, while band $\mathrm{B}$ has a partially resolved 890 $\pm 20 \mathrm{~cm}^{-1}$ progression that is evidently broadened by lower frequency modes. Spectra measured with laser polarization perpendicular and parallel to the electron trajectory were identical; $\beta \approx 0$.

Figure 4(a) shows the four lowest energy anion structures found computationally, along with the corresponding 


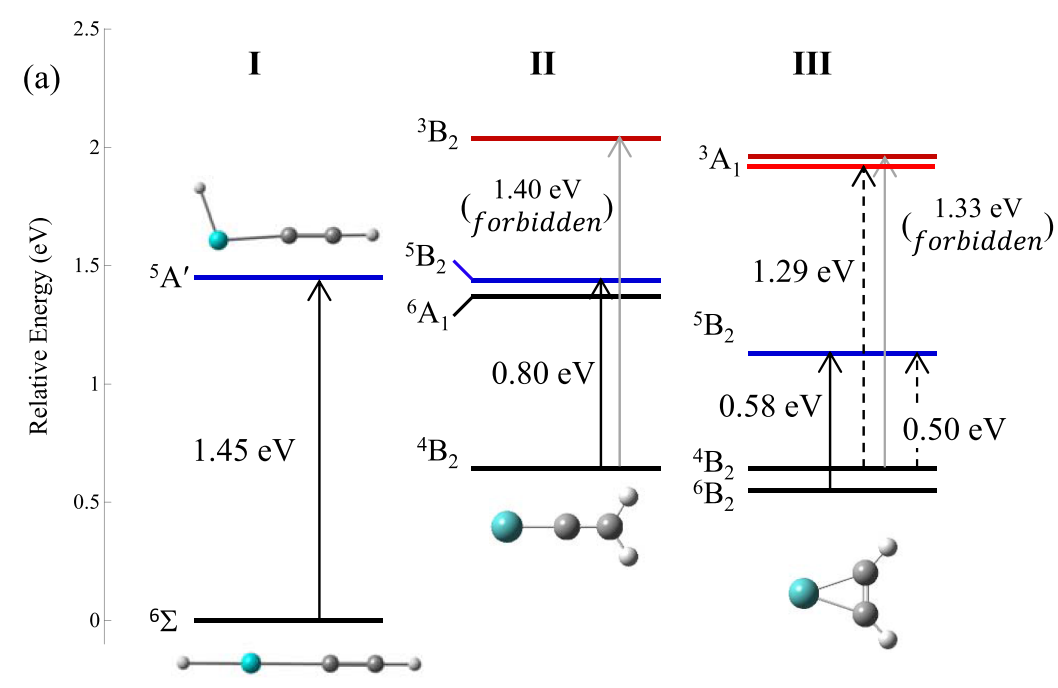

(b)
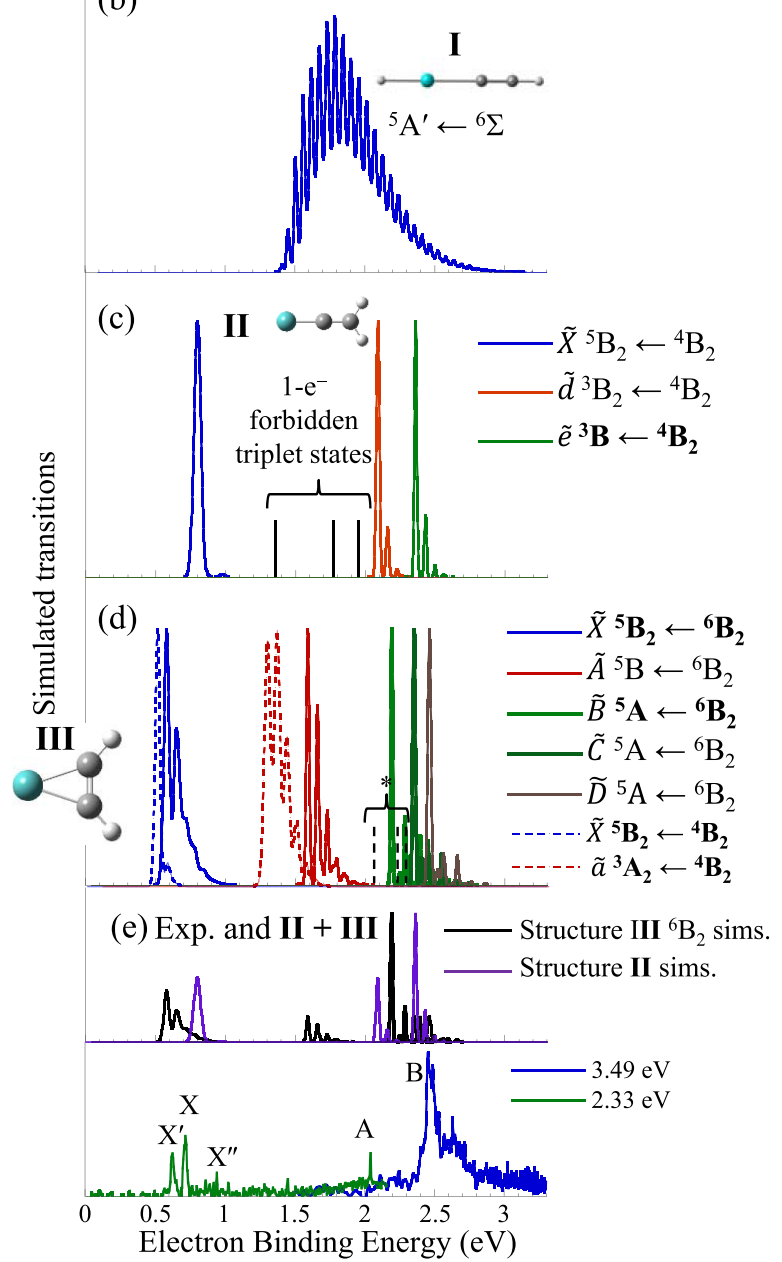

FIG. 3. (a) The three lowest energy structures found computationally for $\mathrm{MoC}_{2} \mathrm{H}_{2}$ anion and neutral. The black horizontal lines reflect the anion zero-point corrected energies (in the case of structures II and III, both the quartet and sextet state energies are shown). The lowest energy neutral spin state energies are indicated with blue lines, and higher energy spin states are indicated with red lines. (b)-(e) Simulations based on the calculated spectroscopic parameters (tabulated in the supplementary material), with transitions to the two neutral spin states color coded to match panel (a). neutrals, with relative energies and ADE values summarized in Table III. Additional structures are included in the supplementary material. The lowest energy structure is a $D_{2 d}$ twisted bowtie (structure I) in an ${ }^{4} \mathrm{~A}_{2}$ electronic state, with two $\eta^{2}-$ acetylene ligands. $\mathrm{A} \mathrm{C}_{2 \mathrm{v}}$ metallacyclic structure (II) in which a new $\mathrm{C}-\mathrm{C}$ bond is formed is predicted to lie $0.73 \mathrm{eV}$ higher in energy than the bowtie. The analogous neutral is nearly isoenergetic with the distorted $\mathrm{C}_{\mathrm{S}}$ neutral bowtie, the lowest energy neutral structure found computationally. Structures with the
Mo center ligated by the central bond of a butatriene (III) or by two vinylidene groups (IV) are predicted to be approximately $1 \mathrm{eV}$ higher in energy.

From a survey of the transition energies associated with the various structures (Table III), the ADE calculated for the bowtie structure $\mathbf{I}$ is in best agreement with band $\mathrm{X}$. The structures with new $\mathrm{C}-\mathrm{C}$ bond formation have much lower binding energies than what is observed because of the relative instability of anions and stability of their corresponding 

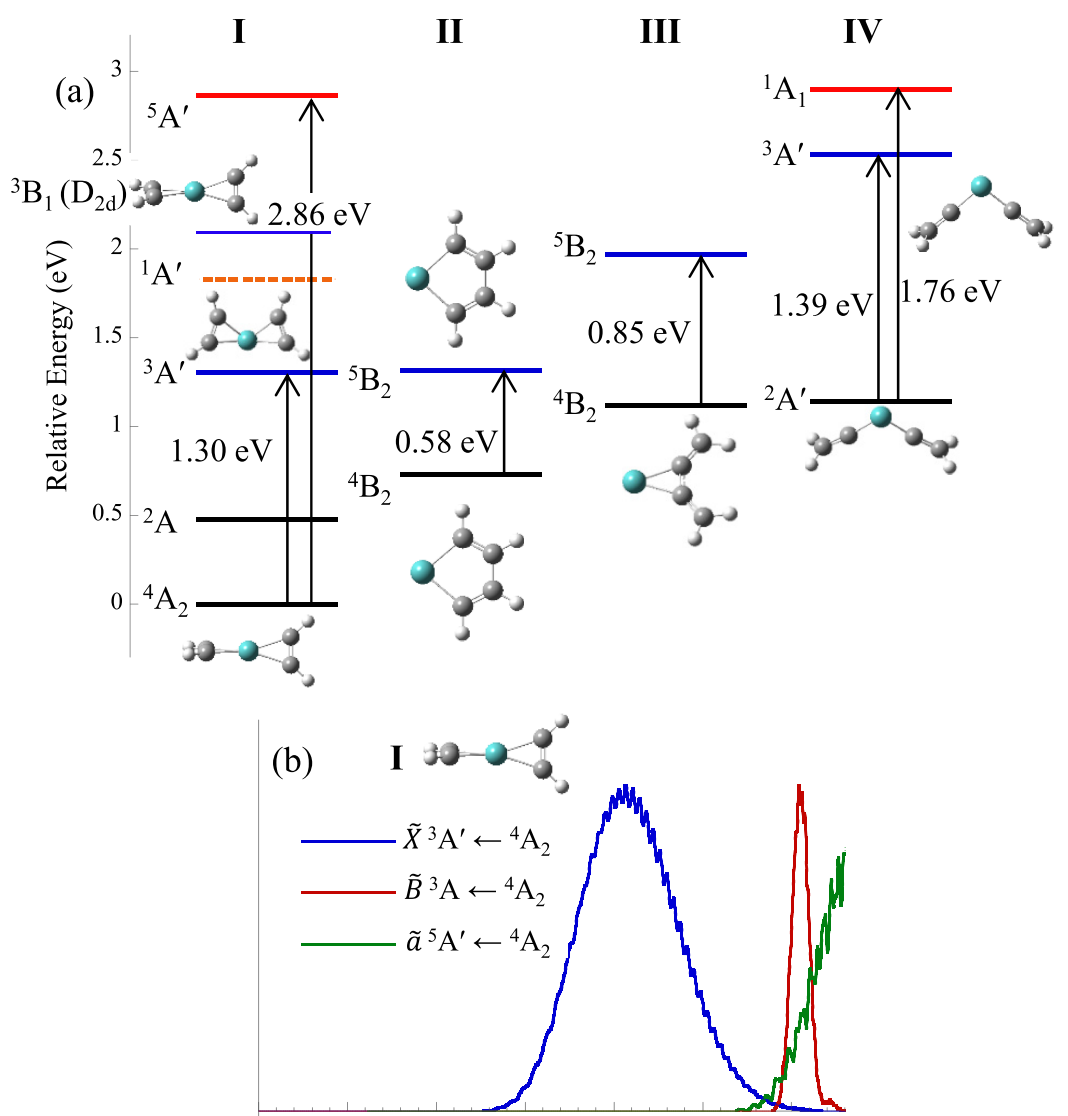

FIG. 4. The four lowest energy structures found computationally for the $\mathrm{MoC}_{4} \mathrm{H}_{4}$ anion and neutral. The black horizontal lines reflect the anion zero-point corrected energies (in the case of structures I and III, two spin state energies are shown). The lowest energy neutral spin state energies are indicated with blue lines, and higher energy spin states are indicated with red lines. Dashed lines indicate neutral states that are spin forbidden in anion detachment transitions. (b)-(d) Simulations based on the calculated spectroscopic parameters (tabulated in the supplementary material), with transitions to the two

(c)

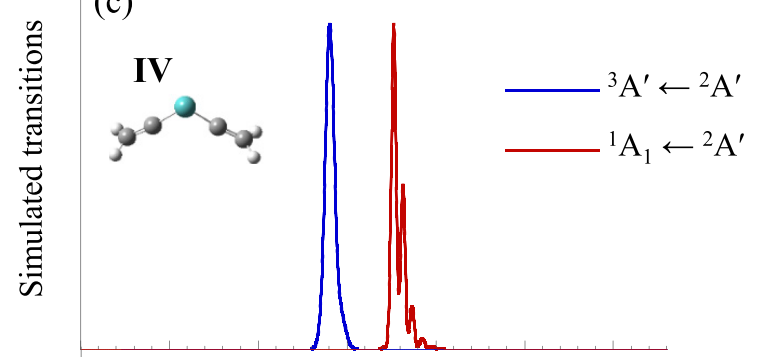
neutral spin states color coded to panel (a).

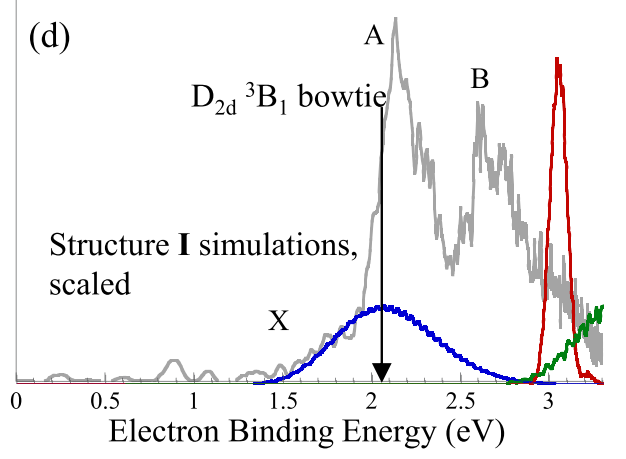

neutrals. In addition, the anions and neutrals of structures II and III are nearly identical, predicting vertical band detachment transitions, which is inconsistent with the observed spectrum.

We consider whether the spectrum of $\mathrm{MoC}_{4} \mathrm{H}_{4}{ }^{-}$can be fully reconciled with the bowtie structure. In addition to the ${ }^{3} \mathrm{~A}^{\prime}$ ground state, the excited ${ }^{5} \mathrm{~A}^{\prime}$ bowtie state, which has significantly extended $\mathrm{Mo}-\mathrm{C}$ bond lengths, should be energetically accessible. The substantial structural differences between the $\mathrm{D}_{2 \mathrm{~d}}{ }^{4} \mathrm{~A}_{2}$ anion ground state and the two neutral states would result in the activation of several low-frequency modes, and the harmonic approximation used in our simulation codes is inappropriate. We therefore used the VDE values to generate broad bands as described in Sec. II B; they are shown in Fig. 4(b). Again, with this open shell anion, there are three singly occupied frontier orbitals; the transition to the lowest energy excited triplet state is indicated by the red trace in Fig. 4(b).

Because the PE spectrum of $\mathrm{MoC}_{2} \mathrm{H}_{2}{ }^{-}$was most consistent with structures predicted to more than $0.5 \mathrm{eV}$ higher 
than the lowest energy anion predicted computationally, we also considered the high-lying di-vinylidine structure (IV) of $\mathrm{MoC}_{4} \mathrm{H}_{4}{ }^{-}$. The simulations associated with the two neutral spin states accessed by photodetachment of the ${ }^{2} \mathrm{~A}_{1}$ anion are shown in Fig. 4(c); both are nearly vertical, as is predicted for detachment transitions associated with structures II and III, and are clearly inconsistent with the observed spectrum.

The two broad band simulations based on the ADE/VDE values for structure $\mathbf{I}$ were scaled to match the relative band intensities in the experimental spectrum in the central panel. Band $\mathrm{A}$ is not accounted for by the overall profile of the ${ }^{3} \mathrm{~A}^{\prime}-{ }^{4} \mathrm{~A}_{2}$ transition. However, the single point energy calculated for a triplet neutral confined to a $\mathrm{D}_{2 \mathrm{~d}}$ bowtie structure is $2.06 \mathrm{eV}$, and we suggest that there may be interesting Franck-Condon effects with what would be a conical intersection on the neutral surface. Again, the simulations do not definitively support the ${ }^{4} \mathrm{~A}_{2}$ ground state structure, but they are consistent with the observed spectrum, and the other competitive structures are not consistent with the observed spectrum.

\section{C. $\mathrm{MoOC}_{2} \mathrm{H}_{2}-/ \mathrm{MoOC}_{2} \mathrm{H}_{2}$}

The PE spectrum of $\mathrm{MoOC}_{2} \mathrm{H}_{2}{ }^{-}$shown in Fig. 2(d) exhibits a low intensity band at $1.68 \mathrm{eV}$, labeled $\mathrm{X}$, and a broad, intense band at $2.1 \mathrm{eV}$, labeled A. Band X exhibits a partially resolved vibrational structure, which will be described in the context of a simulated spectrum below. Band A appears to have shoulders on both the low- and high- $e^{-} B E$ sides, but the profile cannot be empirically simulated with one vibrational frequency. On the low- $e^{-} B E$ side the shoulders are separated by ca. $730 \mathrm{~cm}^{-1}$, while on the high $e^{-} B E$ side, by ca. $1500 \mathrm{~cm}^{-1}$ ( $\mathrm{C}=\mathrm{C}$ stretch frequency). Both bands show similar polarization dependence, with $\beta=0.4$ and 0.5 for bands $\mathrm{X}$ and $\mathrm{A}$, respectively. The transition energies and asymmetry parameters are summarized in Table I.

Figure 5 and Table IV summarize the computational results: the lowest energy structure found for $\mathrm{MoOC}_{2} \mathrm{H}_{2}{ }^{-}$is a $\mathrm{C}_{\mathrm{s}}$ structure (I), again with an $\eta^{2}$-acetylene bond, in a ${ }^{4} \mathrm{~A}^{\prime \prime}$ state. The lower spin state for this structure $\left({ }^{2} \mathrm{~A}\right)$ lies $0.41 \mathrm{eV}$ higher in energy. A Mo-vinylidene structure (II), also in a ${ }^{4} \mathrm{~A}^{\prime \prime}$ state, is $0.73 \mathrm{eV}$ higher in energy. Additional higher lying structures are included in the supplementary material. Simulations based on both structures I and II in their ${ }^{4} \mathrm{~A}^{\prime \prime}$ states undergoing transitions to both the triplet (blue traces) and quintet (red traces) states are shown in Figs. 5(b) and 5(c), respectively. The origin and vibrational structure in the $\eta^{2}$-acetylene (I) ${ }^{3} \mathrm{~A}-{ }^{4} \mathrm{~A}$ " transition is in compelling agreement with band $\mathrm{X}$. The modes contributing to the profile are the $\mathrm{MoO}_{2}$ symmetric stretch $\left(978 \mathrm{~cm}^{-1}\right)$, the $\mathrm{HCCH}$ symmetric bend $\left(798 \mathrm{~cm}^{-1}\right)$, and the Mo- $\left(\eta^{2}\right.$-acetylene) stretch $\left(538 \mathrm{~cm}^{-1}\right)$. All simulation parameters are included in the supplementary material.

The simulations based on the vinylidene structure (II) are not in poor agreement; therefore, we cannot unambiguously assign the spectrum to structure I over II. Moreover, the most intense feature in the experimental spectrum, band $\mathrm{A}$, is not well matched by the transition to the ${ }^{5} \mathrm{~A}^{\prime}$ excited state transition. However, the results of TDDFT calculations

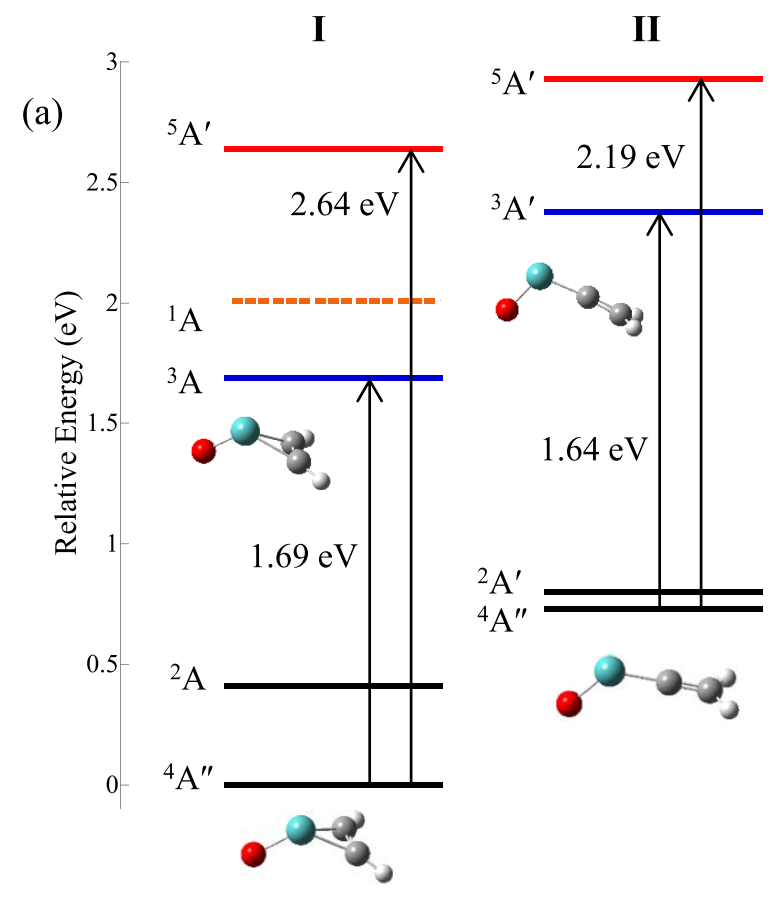

(b)

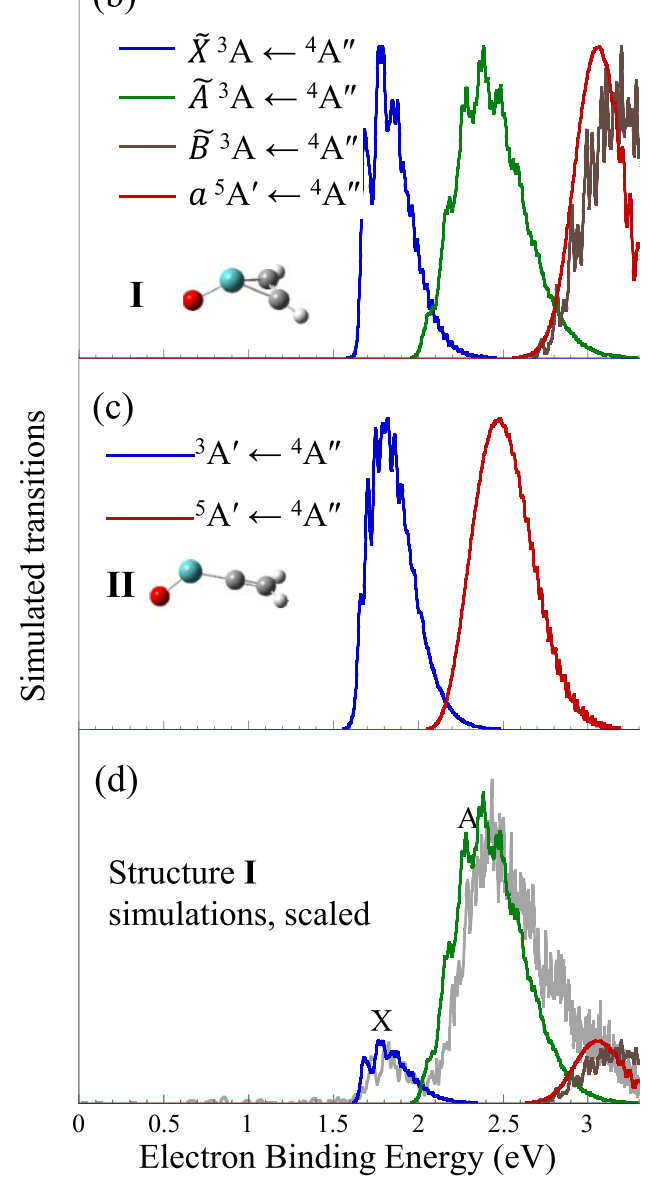

FIG. 5. The two lowest energy structures found computationally for the $\mathrm{MoOC}_{2} \mathrm{H}_{2}$ anion and neutral. The black horizontal lines reflect the anion zeropoint corrected energies (quartet ground states and doublet excited states). The lowest energy neutral spin state energies are indicated with blue lines, and higher energy spin states are indicated with red lines. Dashed lines indicate neutral states that are spin forbidden in anion detachment transitions. (b)-(d) Simulations based on the calculated spectroscopic parameters (tabulated in the supplementary material), with transitions to the two neutral spin states color coded to panel (a). 


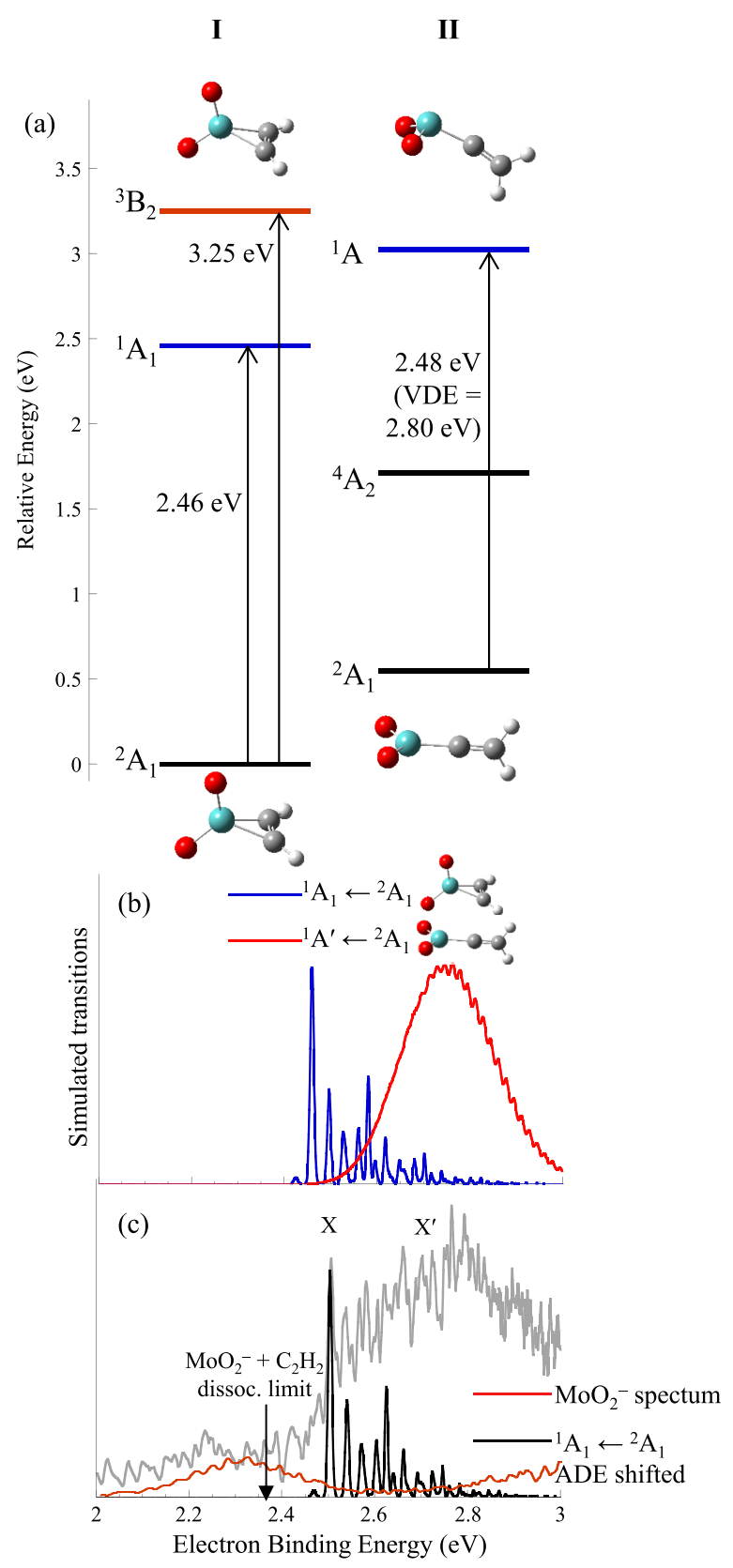

FIG. 6. The two lowest energy structures found computationally for the $\mathrm{MoO}_{2} \mathrm{C}_{2} \mathrm{H}_{2}$ anion and neutral. The black horizontal lines reflect the anion zero-point corrected energies (double and quartet states included for structure II). The lowest energy neutral spin state energies are indicated with blue lines, and higher energy spin states are indicated with red lines. (b) Simulations based on the calculated spectroscopic parameters for structures I (blue) and II (red); parameters are tabulated in the supplementary material. (c) Structure I simulation shifted to $0.050 \mathrm{eV}$ higher binding energy relative to the calculated ADE value to match the PE spectrum. The PE spectrum of $\mathrm{MoO}_{2}{ }^{-}$(Ref. 49) is included for comparison to lower the $e^{-} B E$ signal.

on structure I predict two one-electron allowed transitions to excited triplet states, the lower energy of which has a very similar Franck-Condon profile to band A. Additionally, this lowest energy excited triplet state involves the detachment of an electron from a more Mo $5 s$-like orbital, whereas the ground state transition involves an orbital with more Mo $4 d$ character (as is the transition to the lowest energy ${ }^{5} \mathrm{~A}^{\prime}$ state). Figure 4(d) shows the simulations based on structure I scaled to the experimental transition intensities.
Overall, structure I is very consistent with the experimental spectrum.

\section{D. $\mathrm{MoO}_{2} \mathrm{C}_{2} \mathrm{H}_{2}-/ \mathrm{MoO}_{2} \mathrm{C}_{2} \mathrm{H}_{2}$}

The PE spectrum of $\mathrm{MoO}_{2} \mathrm{C}_{2} \mathrm{H}_{2}{ }^{-}$shown in Fig. 2(e) exhibits continuum signal rising from the baseline at approximately $1.3 \mathrm{eV}$, with a sharp transition labeled $\mathrm{X}$ at $2.5 \mathrm{eV}$ embedded in a broad, congested band of signal labeled $\mathrm{X}^{\prime}$ that reaches the maximum intensity at $2.8 \mathrm{eV}$. The asymmetry parameter of band $\mathrm{X}$ is 0.3 , while band $\mathrm{X}^{\prime}$ has an isotropic distribution; thus bands $\mathrm{X}$ and $\mathrm{X}^{\prime}$ correspond to different electronic transitions. In addition, there are low-intensity local maxima in the continuum signal at approximately $1.75 \mathrm{eV}$ and $2.25 \mathrm{eV}$.

Figure 6(a) and Table $\mathrm{V}$ summarize the computational results on the $\mathrm{MoO}_{2} \mathrm{C}_{2} \mathrm{H}_{2}$ anion and neutral. As noted previously, lower spin states are favored for this more coordinated complex, with singlet neutrals and doublet anions being the ground states for the two structures shown. The more stable structure has $\mathrm{MoO}_{2}$ with an $\eta^{2}$-acetylene ligand (I), with the $\mathrm{MoO}_{2}$ vinylidene complex (II) calculated to be $0.55 \mathrm{eV}$ higher in energy. The $\eta^{2}$-acetylene coordination is computationally energetically favored over the vinylidene coordination for all complexes included in this study.

The simulated spectra based on the spectroscopic parameters calculated for both structures I and II are shown as the blue and red traces, respectively, Fig. 6(b). Figure 6(c) shows the simulation based on structure I (solid black trace) shifted to $0.05 \mathrm{eV}$ higher binding energy relative to the calculated $\mathrm{ADE}$ and superimposed on the experimental spectrum, gray trace, on an expanded scale. While the experimental signal to noise is low, there are coincidences between the vibrationally excited levels in this transition and the experimental signal. The simulation based on the higher lying structure II is not inconsistent with the broad band $\mathrm{X}^{\prime}$, but because band $\mathrm{X}^{\prime}$ is broad and featureless, the assignment is not definitive.

We consider the broad continuum signal arising from the baseline at $e^{-} \mathrm{BE}>1.3 \mathrm{eV}$. The $\mathrm{MoO}_{2}{ }^{-}+\mathrm{C}_{2} \mathrm{H}_{2}$ dissociation limit is calculated to be $2.36 \mathrm{eV}$, well below the $3.49 \mathrm{eV}$ photon energy used to measure the spectrum. The PE spectrum of internally cold $\mathrm{MoO}_{2}{ }^{-}$obtained previously ${ }^{49}$ [red trace, Fig. 6(c)] shows a band maximum near $2.25 \mathrm{eV}$ associated with the ${ }^{3} \mathrm{~B}_{1}-{ }^{4} \mathrm{~B}_{1}$ transition between the anion and neutral ground states, close to the local maximum in the continuum signal. Additionally, the photodissociation of the doublet spin state of $\mathrm{MoO}_{2} \mathrm{C}_{2} \mathrm{H}_{2}{ }^{-}$may form significant quantities of $\mathrm{MoO}_{2}{ }^{-}$in the excited doublet spin state, from which transitions to the $\mathrm{MoO}_{2}$ ${ }^{3} \mathrm{~B}_{1}$ neutral ground state would be at lower $e^{-} B E$. Therefore, we suggest that the continuum signal in the low- $e^{-} B E$ portion of the PE spectrum of $\mathrm{MoO}_{2} \mathrm{C}_{2} \mathrm{H}_{2}{ }^{-}$is due to the photodetachment of $\mathrm{MoO}_{2}{ }^{-}$in a broad distribution of excited electronic and vibrational states formed from the photodissociation of the complex.

\section{DISCUSSION}

The overarching goal of this study is to determine how ethylene interacts with molybdenum suboxide clusters in an 
TABLE II. CCSD(T) calculated zero-point corrected relative energies of $\mathrm{MoC}_{2} \mathrm{H}_{2}$ anion and neutral structures I through III shown in Fig. 3, along with ADE values for one-electron allowed transitions. Additional structures are included in the supplementary material.

\begin{tabular}{|c|c|c|c|c|c|c|}
\hline \multirow{3}{*}{$\begin{array}{l}\text { Structure } \\
\mathrm{MoC}_{2} \mathrm{H}_{2}\end{array}$} & \multirow[t]{2}{*}{ Electronic state } & \multirow[t]{2}{*}{$\left\langle S^{2}\right\rangle^{\mathrm{a}}$} & \multirow[t]{3}{*}{ Relative energy (eV) } & \multirow[t]{2}{*}{$\mathrm{ADE}(\mathrm{eV})$} & \multicolumn{2}{|c|}{ Exp. ADE (eV) } \\
\hline & & & & & $\mathrm{A}, \mathrm{B}$ & $2.03(5), 2.41(5)$ \\
\hline & & & & & $X^{\prime \prime}$ & $0.92(4)$ \\
\hline III & $\tilde{D}^{5} \mathrm{~A}$ & & 3.10 & $2.55^{\mathrm{b}}$ & & \\
\hline II & $\tilde{e}^{3} \mathrm{~B}$ & $\ldots$ & 3.07 & $2.43^{\mathrm{b}}$ & & \\
\hline III & $\tilde{C}^{5} \mathrm{~A}$ & $\ldots$ & 2.95 & $2.40^{\mathrm{b}}$ & & \\
\hline III & $\tilde{B}^{5} \mathrm{~A}$ & $\ldots$ & 2.81 & $2.26^{\mathrm{b}}$ & & \\
\hline II & $\tilde{d}^{3} \mathrm{~B}_{2}$ & $\ldots$ & 2.80 & $2.16^{\mathrm{b}}$ & & \\
\hline III & $\tilde{A}^{5} \mathrm{~B}$ & $\ldots$ & 2.16 & $1.61^{\mathrm{b}}$ & & \\
\hline II & $\tilde{a}^{3} \mathrm{~B}_{2}$ & $2.11^{\mathrm{c}}$ & 2.04 & forbidden & & \\
\hline III & $\tilde{b}^{3} \mathrm{~A}_{1}$ & 2.16 & 1.96 & forbidden & & \\
\hline III & $\tilde{a}^{3} \mathrm{~A}_{2}$ & 2.00 & 1.92 & $1.29^{\mathrm{d}}$ & & \\
\hline $\mathbf{I}$ & ${ }^{5} \mathrm{~A}^{\prime}$ & 6.03 & 1.45 & 1.45 & & \\
\hline II & $\tilde{X}^{5} \mathrm{~B}_{2}$ & 6.25 & 1.44 & 0.80 & $\mathrm{X}$ & $0.718(10)$ \\
\hline III & $\tilde{X}^{5} \mathrm{~B}_{2}$ & 6.01 & 1.13 & $0.58,0.50^{\mathrm{e}}$ & $\mathrm{X}^{\prime}$ & $0.626(10)$ \\
\hline \multicolumn{7}{|l|}{$\mathrm{MoC}_{2} \mathrm{H}_{2}^{-}$} \\
\hline II & ${ }^{6} \mathrm{~A}_{1}$ & 8.93 & 1.31 & & & \\
\hline III & ${ }^{4} \mathrm{~B}_{2}$ & 4.03 & 0.63 & & & \\
\hline III & ${ }^{6} \mathrm{~B}_{2}$ & 8.75 & 0.55 & & & \\
\hline II & ${ }^{4} \mathrm{~B}_{2}$ & $3.82^{\mathrm{c}}$ & 0.54 & & & \\
\hline I & ${ }^{6}{ }_{\Sigma}$ & 8.75 & 0 & & & \\
\hline
\end{tabular}

a $\left\langle S^{2}\right\rangle$ value after projecting out the first spin contaminant.

${ }^{\mathrm{b}}$ TDDFT excited state energies added to $\operatorname{CCSD}(\mathrm{T})$ relative energies. ${ }^{\mathrm{c}}\left\langle S^{2}\right\rangle$ value from Brueckner orbitals.

${ }^{\mathrm{d} 3} \mathrm{~A}_{2} \leftarrow{ }^{4} \mathrm{~B}_{2}$ electronic hot band transition energy.

${ }^{\mathrm{e}} \mathrm{ADE}$ values for the ${ }^{5} \mathrm{~B}_{2}-{ }^{6} \mathrm{~B}_{2}$ and ${ }^{5} \mathrm{~B}_{2}-{ }^{4} \mathrm{~B}_{2}$ transitions, respectively.

effort to inform computational studies on the chemistry of olefins used as a sacrificial reagent in the catalytic production of $\mathrm{H}_{2}$ from water over the molybdenum oxide catalyst.
There are several results from previous experiments to take into account. ${ }^{34}$ (1) Reactions between $\mathrm{C}_{2} \mathrm{H}_{4}$ and the most reduced $\mathrm{Mo}_{x} \mathrm{O}_{y}{ }^{-}$clusters in the distribution of stoichiometries formed

TABLE III. CCSD(T) calculated zero-point corrected relative energies of $\mathrm{MoC}_{4} \mathrm{H}_{4}$ anion and neutral structures I-IV shown in Fig. 4, along with transition energies for one-electron allowed transitions. VDE values are included for transitions that are predicted to be broadened by the activation of multiple low-frequency modes. Additional structures are included in the supplementary material.

\begin{tabular}{|c|c|c|c|c|c|c|c|}
\hline Structure & Electronic state & $\left\langle S^{2}\right\rangle^{\mathrm{a}}$ & Relative energy (eV) & $\mathrm{ADE}(\mathrm{eV})$ & VDE (eV) & \multicolumn{2}{|c|}{ Exp. ADE (eV) } \\
\hline $\mathrm{MoC}_{4} \mathrm{H}_{4}$ & & & & & & $\mathrm{~B}$ & $2.5(2)$ \\
\hline $\mathbf{I}$ & $\tilde{B}^{3} \mathrm{~A}$ & $\ldots$ & 3.07 & $3.07^{\mathrm{b}}$ & & & \\
\hline $\mathbf{I}$ & $\tilde{a}^{5} \mathrm{~A}^{\prime}$ & 6.05 & 2.93 & 2.76 & 3.64 & & \\
\hline IV & ${ }^{1} \mathrm{~A}_{1}$ & 0.00 & 2.90 & 1.76 & & & \\
\hline IV & ${ }^{3} \mathrm{~A}^{\prime}$ & $2.03^{\mathrm{c}}$ & 2.53 & 1.39 & & & \\
\hline $\mathbf{I}$ & ${ }^{3} \mathrm{~B}_{1}$ & & 2.06 & & $2.06^{\mathrm{d}}$ & A & $2.0(1)$ \\
\hline III & ${ }^{5} \mathrm{~B}_{2}$ & 6.07 & 1.97 & 0.85 & & & \\
\hline I & ${ }^{1} \mathrm{~A}^{\prime}$ & 0.00 & 1.75 & Forbidden & & & \\
\hline II & ${ }^{5} \mathrm{~B}_{2}$ & 6.03 & 1.31 & 0.58 & & & \\
\hline I & $\tilde{X}^{3} \mathrm{~A}^{\prime}$ & 2.03 & 1.30 & 1.30 & 2.10 & $\mathrm{X}$ & $1.5(1)$ \\
\hline \multicolumn{8}{|l|}{$\mathrm{MoC}_{4} \mathrm{H}_{4}^{-}$} \\
\hline III & ${ }^{6} \mathrm{~B}_{2}$ & 8.77 & 1.16 & & & & \\
\hline IV & ${ }^{2} \mathrm{~A}^{\prime}$ & 0.75 & 1.14 & & & & \\
\hline III & ${ }^{4} \mathrm{~B}_{2}$ & 4.27 & 1.12 & & & & \\
\hline II & ${ }^{4} \mathrm{~B}_{2}$ & 4.07 & 0.73 & & & & \\
\hline $\mathbf{I}$ & ${ }^{2} \mathrm{~A}^{\prime}$ & 0.75 & 0.48 & & & & \\
\hline $\mathbf{I}$ & ${ }^{4} \mathrm{~A}_{2}$ & 3.75 & 0 & & & & \\
\hline
\end{tabular}

${ }^{\mathrm{a}}\left\langle S^{2}\right\rangle$ value after projecting out the first spin contaminant.

${ }^{\mathrm{b}}$ TDDFT excited state energies added to $\operatorname{CCSD}(\mathrm{T})$ relative energies.

${ }^{\mathrm{c}}\left\langle S^{2}\right\rangle$ value from Brueckner orbitals.

${ }^{d} D_{2 d}$ neutral structure single point energy. 
TABLE IV. CCSD(T) calculated zero-point corrected relative energies of $\mathrm{MoOC}_{2} \mathrm{H}_{2}$ anion and neutral structures I and II shown in Fig. 5, along with transition energies for one-electron allowed transitions. VDE values are included for transitions that are predicted to be broadened by the activation of multiple low-frequency modes. Additional structures are included in the supplementary material.

\begin{tabular}{|c|c|c|c|c|c|c|c|}
\hline \multirow{2}{*}{$\frac{\text { Structure }}{\mathrm{MoOC}_{2} \mathrm{H}_{2}}$} & \multirow[t]{2}{*}{ Electronic state } & \multirow[t]{2}{*}{$\left\langle S^{2}\right\rangle^{\mathrm{a}}$} & \multirow[t]{2}{*}{ Relative energy (eV) } & \multirow{2}{*}{$\mathrm{ADE}(\mathrm{eV})$} & \multirow[t]{2}{*}{$\mathrm{VDE}(\mathrm{eV})$} & \multicolumn{2}{|c|}{ Exp. ADE $(e V)$} \\
\hline & & & & & & A & $2.1(1)$ \\
\hline II & ${ }^{5} \mathrm{~A}^{\prime}$ & 6.05 & 2.93 & 2.19 & & & \\
\hline $\mathbf{I}$ & $\tilde{B}^{3} \mathrm{~A}$ & $\ldots$ & 2.81 & $2.81^{\mathrm{b}}$ & & & \\
\hline $\mathbf{I}$ & $\tilde{a}^{5} \mathrm{~A}^{\prime}$ & 6.02 & 2.64 & 2.64 & 3.47 & & \\
\hline II & ${ }^{3} \mathrm{~A}^{\prime}$ & $2.01^{\mathrm{c}}$ & 2.38 & 1.64 & & & \\
\hline $\mathbf{I}$ & $\tilde{A}^{3} \mathrm{~A}$ & $\ldots$ & 2.08 & $2.08^{\mathrm{b}}$ & & & \\
\hline I & ${ }^{1} \mathrm{~A}$ & 0.00 & 2.01 & forbidden & & & \\
\hline I & $\tilde{X}^{3} \mathrm{~A}$ & 2.18 & 1.69 & 1.69 & 1.88 & $\mathrm{X}$ & $1.68(7)$ \\
\hline \multicolumn{8}{|l|}{$\mathrm{MoOC}_{2} \mathrm{H}_{2}^{-}$} \\
\hline II & ${ }^{2} \mathrm{~A}^{\prime}$ & 0.77 & 0.80 & & & & \\
\hline II & ${ }^{4} \mathrm{~A}^{\prime \prime}$ & 4.02 & 0.73 & & & & \\
\hline I & ${ }^{2} \mathrm{~A}$ & 0.92 & 0.41 & & & & \\
\hline I & ${ }^{4} \mathrm{~A}^{\prime \prime}$ & 3.76 & 0 & & & & \\
\hline
\end{tabular}

${ }^{\mathrm{a}}\left\langle S^{2}\right\rangle$ value after projecting out the first spin contaminant.

${ }^{\mathrm{b}}$ TDDFT excited state energies added to $\operatorname{CCSD}(\mathrm{T})$ relative energies.

${ }^{\mathrm{c}}\left\langle S^{2}\right\rangle$ value from Brueckner orbitals.

in our cluster source result in the production of chemifragment complex anions. Calculations on the thermodynamics of these reactions support the participation of more than one ethylene molecule in the formation of these complexes. ${ }^{34}$ (2) In reactions with $\mathrm{C}_{2} \mathrm{H}_{4}$, most of the chemifragment complexes observed feature $\mathrm{C}_{2} \mathrm{H}_{2}$, evocative of oxidative dehydrogenation. (3) In co-reactions with water under conditions in which the number density of water is $10^{-3}$ that of the number density of $\mathrm{C}_{2} \mathrm{H}_{4}$, the more oxidized chemifragments, particularly, $\mathrm{MoO}_{2} \mathrm{C}_{2} \mathrm{H}_{2}^{-}$, become more dominant. This result suggests either that the different fragments originate from the fragmentation of different clusters, since the rapid kinetics of reactions between profoundly reduced clusters such as $\mathrm{Mo}_{2} \mathrm{O}_{2}{ }^{-}$ and $\mathrm{Mo}_{3} \mathrm{O}_{3}{ }^{-}$are such that these species would be eliminated from the reactor prior to forming chemifragments in reactions with $\mathrm{C}_{2} \mathrm{H}_{4}$, or that the small complexes undergo oxidation in reactions with water.

The results of the current spectroscopic and computational study suggest that $\eta^{2}$-acetylene complexes are formed for all four species, though we cannot unambiguously rule out the presence of vinylidene complexes. With the exception of $\mathrm{MoO}_{2} \mathrm{C}_{2} \mathrm{H}_{2}^{-}$, the complex anions and neutrals are in high spin states, as opposed to being stable, closed-shell fragments. In the case of $\mathrm{MoC}_{2} \mathrm{H}_{2}{ }^{-}$in particular, the lowest energy structural isomer of the anion identified computationally cannot be reconciled with the experimental spectra, while higher energy structures are in parity with the spectrum. We have observed kinetically trapped, thermodynamically unfavored structures resulting from cluster-water and cluster-alcohol reactions in the previous studies. $26,28,31,49,50$

In combination with the observations listed in the previous paragraphs, the new results from this current study evoke a picture of $\pi$-electron donation to Mo centers, with adjacent $\mathrm{Mo}-\mathrm{H}$ or $\mathrm{H}-\mathrm{O}-\mathrm{Mo}$ bond formation, and kinetically controlled fragment formation. A similar mechanism has been invoked in the oxidative dehydrogenation of alkanes over bulk $\mathrm{MoO}_{3} .{ }^{51}$ While Mo centers in the more reduced clusters are less acidic, they are less hindered than metal centers in more

TABLE V. CCSD(T) calculated zero-point corrected relative energies of $\mathrm{MoO}_{2} \mathrm{C}_{2} \mathrm{H}_{2}$ anion and neutral structures I and II shown in Fig. 6, along with transition energies for one-electron allowed transitions. VDE values are included for transitions that are predicted to be broadened by the activation of multiple low-frequency modes. Additional structures are included in the supplementary material.

\begin{tabular}{|c|c|c|c|c|c|c|c|}
\hline & Electronic state & $\left\langle S^{2}\right\rangle^{\mathrm{a}}$ & Relative energy $(\mathrm{eV})$ & $\mathrm{ADE}(\mathrm{eV})$ & VDE $(e V)$ & \multicolumn{2}{|c|}{ Exp. ADE/VDE (eV) } \\
\hline \multicolumn{8}{|c|}{$\mathrm{MoO}_{2} \mathrm{C}_{2} \mathrm{H}_{2}$} \\
\hline I & ${ }^{3} \mathrm{~B}_{2}$ & 2.03 & 3.25 & 3.25 & 3.96 & & \\
\hline II & ${ }^{1} \mathrm{~A}^{\prime}$ & 0.00 & 3.02 & 2.48 & 2.80 & $X^{\prime}$ & $2.4(2) / 2.8(2)$ \\
\hline $\mathbf{I}$ & ${ }^{1} \mathrm{~A}_{1}$ & 0.00 & 2.46 & 2.46 & & $\mathrm{X}$ & $2.51(7) / 2.6(1)$ \\
\hline \multicolumn{8}{|c|}{$\mathrm{MoO}_{2} \mathrm{C}_{2} \mathrm{H}_{2}^{-}$} \\
\hline II & ${ }^{4} \mathrm{~A}$ & 3.76 & 1.71 & & & & \\
\hline II & ${ }^{2} \mathrm{~A}_{1}$ & 0.76 & 0.55 & & & & \\
\hline I & ${ }^{2} \mathrm{~A}_{1}$ & 0.76 & 0 & & & & \\
\hline
\end{tabular}

${ }^{\mathrm{a}}\left\langle S^{2}\right\rangle$ value after projecting out the first spin contaminant. 
oxidized clusters. In addition, the structures we have determined for the more reduced clusters, ${ }^{52,53}$ the weakest bonds are direct Mo-Mo bonds (not present in more oxidized clusters) that would be the most vulnerable to bond breaking given the large internal energy gained upon new bond formation upon reaction. A follow-up computational study will consider the free energy pathway of this mechanism.

Previous studies on $\mathrm{Mo}_{x} \mathrm{O}_{y}{ }^{-}+\mathrm{CH}_{4}$ and $\mathrm{C}_{2} \mathrm{H}_{6}$ reactions also showed evidence of cluster fragmentation. Subsequent computational studies ${ }^{54}$ on $\mathrm{Mo}_{2} \mathrm{O}_{y}{ }^{-}+\mathrm{CH}_{4}$ reactions indicated that the overall reaction barriers are much lower when a second methane molecule adds prior to $\mathrm{Mo}_{2} \mathrm{O}_{y}{ }^{-}(y=2-5)$ cleavage. Our previously reported reaction free energies calculated for potential fragmentation reactions involving ethylene indicate that several of the reactions involving a single $\mathrm{C}_{2} \mathrm{H}_{4}$ molecule are modestly unfavorable, while reactions with two $\mathrm{C}_{2} \mathrm{H}_{4}$ molecules are favorable, particularly if the reduction of $\mathrm{C}_{2} \mathrm{H}_{4}$ is featured in the reaction. ${ }^{34}$ Calculations also indicate that oxidative addition of a second $\mathrm{C}_{2} \mathrm{H}_{4}$ to a Mo-center in larger $\mathrm{Mo}_{x} \mathrm{O}_{y}{ }^{-}$clusters favors subsequent $\mathrm{Mo}-\mathrm{Mo}$ bond cleavage, and yields a stable neutral fragment.

\section{CONCLUSIONS}

$\mathrm{MoC}_{2} \mathrm{H}_{2}{ }^{-}, \mathrm{MoC}_{4} \mathrm{H}_{4}{ }^{-}, \mathrm{MoOC}_{2} \mathrm{H}_{2}{ }^{-}$, and $\mathrm{MoO}_{2} \mathrm{C}_{2} \mathrm{H}_{2}{ }^{-}$ complex anions were previously found to form from chemifragmentation reactions between $\mathrm{Mo}_{x} \mathrm{O}_{y}{ }^{-}$cluster anions and $\mathrm{C}_{2} \mathrm{H}_{4}$. To determine the molecular-scale interactions along the chemifragmentation pathways, the anion PE spectra of these complexes, along with supporting density functional theory and $\operatorname{CCSD}(\mathrm{T})$ calculations, were analyzed. The spectra of these complexes are all consistent with the calculated $\eta^{2}$-acetylene complexes, though for all but $\mathrm{MoC}_{4} \mathrm{H}_{4}{ }^{-}$, the possibility that vinylidene complexes are also present cannot be definitively ruled out. The structures most consistent with the $\mathrm{MoC}_{2} \mathrm{H}_{2}{ }^{-}$spectrum are high energy structures, suggesting that the chemifragmentation reaction is under kinetic, rather than thermodynamic, control. The PE spectrum of $\mathrm{MoO}_{2} \mathrm{C}_{2} \mathrm{H}_{2}{ }^{-}$additionally exhibits evidence that photodissociation to $\mathrm{MoO}_{2}{ }^{-}+\mathrm{C}_{2} \mathrm{H}_{2}$ may be occurring. The results suggest that oxidative dehydrogenation of ethylene is initiated by Lewis acid/base interactions between the Mo centers in larger clusters and the $\pi$ orbitals in ethylene.

\section{SUPPLEMENTARY MATERIAL}

See supplementary material for parameters used to generate the PE spectral simulations, a comparison of $\operatorname{CCSD}(\mathrm{T})$ and B3LYP relative energies, figures showing additional higher energy anion and neutral structures not included in the manuscript (Cartesian coordinates are available upon request), and the frontier orbitals and occupancies for the most competitive structures of the species described in this report.

\section{ACKNOWLEDGMENTS}

This work is supported in its entirety by the U.S. Department of Energy, Office of Basic Energy Sciences, under
Award No. DE-FG02-07ER15889, at Indiana University, Bloomington.

${ }^{1}$ S. Pullen and S. Ott, Top. Catal. 59, 1712 (2016).

${ }^{2}$ K. Natarajan, T. S. Natarajan, R. I. Kureshy, H. C. Bajaj, W. K. Jo, and R. J. Tayade, Adv. Mater. Res. 1116, 130 (2015).

${ }^{3}$ P. D. Tran, T. V. Tran, M. Orio, S. Torelli, Q. D. Truong, K. Nayuki, Y. Sasaki, S. Y. Chiam, R. Yi, I. Honma, J. Barber, and V. Artero, Nat. Mater. 15, 640 (2016).

${ }^{4}$ A. Saha and K. Raghavachari, J. Chem. Phys. 139, 204301 (2013).

${ }^{5}$ A. Saha and K. Raghavachari, J. Chem. Phys. 141, 074305 (2014).

${ }^{6}$ S. Rangarajan and M. Mavrikakis, ACS Catal. 6, 2904 (2016).

${ }^{7}$ S. Y. Ryu, J. Choi, W. Balcerski, T. K. Lee, and M. R. Hoffmann, Ind. Eng. Chem. Res. 46, 7476 (2007).

${ }^{8}$ K. A. Brown, M. B. Wilker, M. Boehm, G. Dukovic, and P. W. King, J. Am. Chem. Soc. 134, 5627 (2012).

${ }^{9}$ Z. Luo, R. Miao, T. D. Huan, I. M. Mosa, A. S. Poyraz, W. Zhong, J. E. Cloud, D. A. Kriz, S. Thanneeru, J. He, Y. Zhang, R. Ramprasad, and S. L. Suib, Adv. Energy Mater. 6, 1600528 (2016).

${ }^{10}$ T.-G. Truong, C. Meriadec, B. Fabre, J.-F. Bergamini, O. de Sagazan, S. Ababou-Girard, and G. Loget, Nanoscale 9, 1799 (2017).

${ }^{11}$ G. Pacchioni, Chem. Phys. Chem. 4, 1041 (2003).

${ }^{12}$ U. S. Ozkan and R. B. Watson, Catal. Today 100, 101 (2005).

${ }^{13}$ R. A. J. O'Hair, Int. J. Mass Spectrom. 377, 121 (2015).

${ }^{14}$ R. C. Bell, K. A. Zemski, and A. W. Castleman, Jr., J. Cluster Sci. 10, 509 (1999).

${ }^{15}$ G. E. Johnson, E. C. Tyo, and A. W. Castleman, Proc. Natl. Acad. Sci. U. S. A. 105, 18108 (2008).

${ }^{16}$ A. W. Castleman, Jr., Catal. Lett. 141, 1243 (2011).

${ }^{17}$ I. S. Parry, A. Kartouzian, S. M. Hamilton, O. P. Balaj, M. K. Beyer, and S. R. Mackenzie, Angew. Chem., Int. Ed. 54, 1357 (2015).

${ }^{18}$ F. Dong, S. Heinbuch, Y. Xie, J. J. Rocca, E. R. Bernstein, Z. C. Wang, K. Deng, and S. G. He, J. Am. Chem. Soc. 130, 1932 (2008).

${ }^{19}$ Z. C. Wang, S. Yin, and E. R. Bernstein, J. Chem. Phys. 139, 194313 (2013).

${ }^{20}$ S. Hirabayashi and M. Ichihashi, J. Phys. Chem. A 117, 9005 (2013).

${ }^{21}$ M. Tombers, L. Barzen, and G. Niedner-Schatteburg, J. Phys. Chem. A 117, 1197 (2013)

${ }^{22}$ S. Li, C. L. Guenther, M. S. Kelley, and D. A. Dixon, J. Phys. Chem. C 115, 8072 (2011)

${ }^{23}$ A. C. Reber, S. N. Khanna, E. C. Tyo, C. L. Harmon, and A. W. Castleman, Jr., J. Chem. Phys. 135, 234303 (2011).

${ }^{24}$ E. C. Tyo, A. W. Castleman, Jr., A. C. Reber, and S. N. Khanna, J. Phys. Chem. C 115, 16797 (2011).

${ }^{25}$ G. E. Johnson, J. U. Reveles, N. M. Reilly, E. C. Tyo, S. N. Khanna, and A. W. Castleman, Jr., J. Phys. Chem. A 112, 11330 (2008).

${ }^{26}$ D. W. Rothgeb, J. Mann, and C. C. Jarrold, J. Chem. Phys. 133, 054305 (2010).

${ }^{27}$ D. W. Rothgeb, E. Hossain, N. J. Mayhall, K. Raghavachari, and C. C. Jarrold, J. Chem. Phys. 131, 144306 (2009).

${ }^{28}$ D. W. Rothgeb, E. Hossain, A. T. Kuo, J. L. Troyer, C. C. Jarrold, N. J. Mayhall, and K. Raghavachari, J. Chem. Phys. 130, 124314 (2009).

${ }^{29}$ J. O. Kafader, M. Ray, K. Raghavachari, and C. C. Jarrold, J. Chem. Phys. 144, 074307 (2016).

${ }^{30}$ R. Ramabhadran, J. E. Mann, S. E. Waller, D. W. Rothgeb, C. C. Jarrold, and K. Raghavachari, J. Am. Chem. Soc. 135, 17039 (2013).

${ }^{31}$ N. J. Mayhall, D. W. Rothgeb, E. Hossain, C. C. Jarrold, and K. Raghavachari, J. Chem. Phys. 131, 144302 (2009).

${ }^{32}$ M. Ray, S. E. Waller, A. Saha, K. Raghavachari, and C. C. Jarrold, J. Chem. Phys. 141, 104310 (2014).

${ }^{33}$ M. Ray, A. Saha, and K. Raghavachari, Phys. Chem. Chem. Phys. 18, 25687 (2016).

${ }^{34}$ M. Ray, R. N. Schaugaard, J. E. Topolski, J. O. Kafader, K. Raghavachari, and C. C. Jarrold, J. Phys. Chem. A 122, 41 (2018).

${ }^{35}$ V. D. Moravec and C. C. Jarrold, J. Chem. Phys. 108, 1804 (1998).

${ }^{36}$ S. E. Waller, J. E. Mann, D. W. Rothgeb, and C. C. Jarrold, J. Phys. Chem. A 116, 9639 (2012).

${ }^{37}$ J. A. Felton, M. Ray, and C. C. Jarrold, Phys. Rev. A 89, 033407 (2014).

${ }^{38}$ R. F. Gunion, S. J. Dixon-Warren, W. C. Lineberger, and M. D. Morse, J. Chem. Phys. 104, 1765 (1996).

${ }^{39}$ M. J. Frisch, G. W. Trucks, H. B. Schlegel, G. E. Scuseria, M. A. Robb, J. R. Cheeseman, G. Scalmani, V. Barone, G. A. Petersson, H. Nakatsuji, X. Li, M. Caricato, A. Marenich, J. Bloino, B. G. Janesko, R. Gomperts, B. Mennucci, H. P. Hratchian, J. V. Ortiz, A. F. Izmaylov, J. L. Sonnenberg, D. Williams-Young, F. Ding, F. Lipparini, F. Egidi, J. Goings, 
B. Peng, A. Petrone, T. Henderson, D. Ranasinghe, V. G. Zakrzewski, J. Gao, N. Rega, G. Zheng, W. Liang, M. Hada, M. Ehara, K. Toyota, R. Fukuda, J. Hasegawa, M. Ishida, T. Nakajima, Y. Honda, O. Kitao, H. Nakai, T. Vreven, K. Throssell, J. A. Montgomery, Jr., J. E. Peralta, F. Ogliaro, M. Bearpark, J. J. Heyd, E. Brothers, K. N. Kudin, V. N. Staroverov, T. Keith, R. Kobayashi, J. Normand, K. Raghavachari, A. Rendell, J. C. Burant, S. S. Iyengar, J. Tomasi, M. Cossi, J. M. Millam, M. Klene, C. Adamo, R. Cammi, J. W. Ochterski, R. L. Martin, K. Morokuma, O. Farkas, J. B. Foresman, and D. J. Fox, Gaussian 09, Revision D.01, Gaussian, Inc., Wallingford CT, 2016.

${ }^{40}$ A. D. Becke, Phys. Rev. A 38, 3098 (1988).

${ }^{41}$ C. Lee, W. Yang, and R. G. Parr, Phys. Rev. B 37, 785 (1988).

${ }^{42}$ A. D. Becke, J. Chem. Phys. 98, 5648 (1993).

${ }^{43}$ A. Schäfer, H. Horn, and R. Ahlrichs, J. Chem. Phys. 97, 2571 (1992).

${ }^{44}$ A. Schäfer, C. Huber, and R. Ahlrichs, J. Chem. Phys. 100, 5829 (1994).

${ }^{45}$ S. E. Waller, M. Ray, B. L. Yoder, and C. C. Jarrold, J. Phys. Chem. A 117, 13919 (2013).
${ }^{46}$ D. Andrae, U. Häußermann, M. Dolg, H. Stoll, and H. Preuß, Theor. Chim. Acta 77, 123 (1990).

${ }^{47}$ E. Papajak, J. Zheng, X. Xu, H. R. Leverentz, and D. G. Truhlar, J. Chem. Theory Comput. 7, 3027 (2011).

${ }^{48}$ J. N. Harvey, "DFT computation of relative spin-state energetics of transition metal compounds," in Principles and Applications of Density Functional Theory in Inorganic Chemistry I, Structure and Bonding (Springer, Berlin, Heidelberg, 2004), Vol. 112, pp. 151-184.

${ }^{49}$ R. B. Wyrwas, B. L. Yoder, J. T. Maze, and C. C. Jarrold, J. Phys. Chem. A 110, 2157 (2006).

${ }^{50}$ U. Das, K. Raghavachari, and C. C. Jarrold, J. Chem. Phys. 122, 014313 (2005).

${ }^{51}$ K. Chen, A. T. Bell, and E. Iglesia, J. Phys. Chem. B 104, 1292 (2000).

${ }^{52}$ B. L. Yoder, J. T. Maze, K. Raghavachari, and C. C. Jarrold, J. Chem. Phys. 122, 094313 (2005).

${ }^{53}$ J. E. Mann, N. J. Mayhall, and C. C. Jarrold, Chem. Phys. Lett. 525-526, 1 (2012).

${ }^{54}$ N. J. Mayhall and K. Raghavachari, J. Phys. Chem. A 111, 8211 (2007). 